\title{
Insulin analogues and their potential in the management of diabetes mellitus
}

\author{
G.B. Bolli ${ }^{1}$, R.D. Di Marchi ${ }^{2}$, G.D. Park ${ }^{3}$, S. Pramming 4 , V.A. Koivisto ${ }^{5}$ \\ ${ }^{1}$ University of Perugia, Italy \\ ${ }^{2}$ Lilly Research Laboratories, Indianapolis, Indiana, USA \\ ${ }^{3}$ Hoechst Marion Roussel, Bridgewater, New Jersey, USA \\ ${ }^{4}$ Novo Nordisk, Bagsvaerd, Denmark \\ ${ }^{5}$ Lilly Research Laboratories, Hamburg, Germany
}

Keywords Insulin analogues, insulin pharmacokinetics, insulin pharmacodynamics, physiologic insulin therapy, Type I diabetes mellitus, continuous subcutaneous insulin infusion.

\section{Introduction}

The primary goal of treatment of Type I (insulin-dependent) diabetes mellitus, both at onset and after several years duration, is maintenance of near-normoglycaemia [1] to prevent the onset or delay progression or both of long-term complications [2, 3]. This goal is feasible if physiological models of insulin replacement are used [4] and patients are educated with the strategy of intensive insulin therapy [5-7]. Under these conditions, glycosylated haemoglobin $\mathrm{A}_{1 \mathrm{c}}\left(\mathrm{HbA}_{1 \mathrm{c}}\right)$ can be reduced long-term to values lower than $7.0 \%$ and the frequency of hypoglycaemia minimised [5-8]. In a majority of patients, the control is still unsatisfactory, which at least in part can be due to less than optimal insulin therapy [9].

Purified pork and human insulin molecules have a high tendency for self-association to form hexamers, the predominant form present in the insulin vials that patients use. The dissociation rate of human insulin into monomeric molecules is slow at the s.c. site of injection and consequently its absorption is also slow because insulin is absorbed predominantly in the monomeric form. Therefore, pre-prandial treatment with short-acting insulin preparations (pork purified, human) results in a less than optimal increase in portal and peripheral plasma insulin concentrations in the early phase of glucose absorption from the intestine. Consequently blood glucose increases excessively 1 to 2 hours after meal ingestion

Corresponding author: Professor G. B. Bolli, University of Perugia, Di.M.I.S.E.M, Via E. Dal Pozzo, 06126 Perugia, Italy
[10]. Nevertheless, 4 to 5 hours after the s.c. insulin injection, the continuing absorption from the injection site results in inappropriate hyperinsulinaemia which increases the risk for hypoglycaemia because by that time meal absorption is nearly complete [10]. The theoretical combination of a prandial insulin peak with a flat, square-wave interprandial plasma insulin profile, would closely mimic the 24 -h plasma insulin pattern of normal, non-diabetic people who exhibit very tiny blood glucose variations regardless whether in the fed or fasting state (Fig.1) [11].

The above considerations are the rationale for exploring the potential benefits of modified insulin molecules, the so-called analogues of insulin which can be synthesised by means of the rDNA technique. This review follows previous review articles on insulin analogues [12-14]. In this article, the basic characteristics and clinical applications of recently developed short-acting and long-acting insulin analogues are discussed along with their characteristics and safety, as well as indications for potential insulin substitution in Type I diabetes mellitus.

\section{Short-acting analogues}

\section{Background}

The tendency of insulin to self-associate under normal physiological circumstances seems appropriate in the normal beta cell, since it facilitates proinsulin transportation, conversion and intracellular storage of insulin microcrystals [15]. This property becomes, however, one of the obstacles in achieving physiological insulin substitution after s.c. injection of insulin in Type I diabetes mellitus [10].

Chemical synthesis of insulin in the 1960s is the basis for the success of rDNA technologies in the creation of new insulin analogues. Chemical modifications or semisynthesis only had limited potential due to the laborious techniques required. Biosynthesis and protein engineering became necessary techniques, both for the design and large-scale production of mod- 

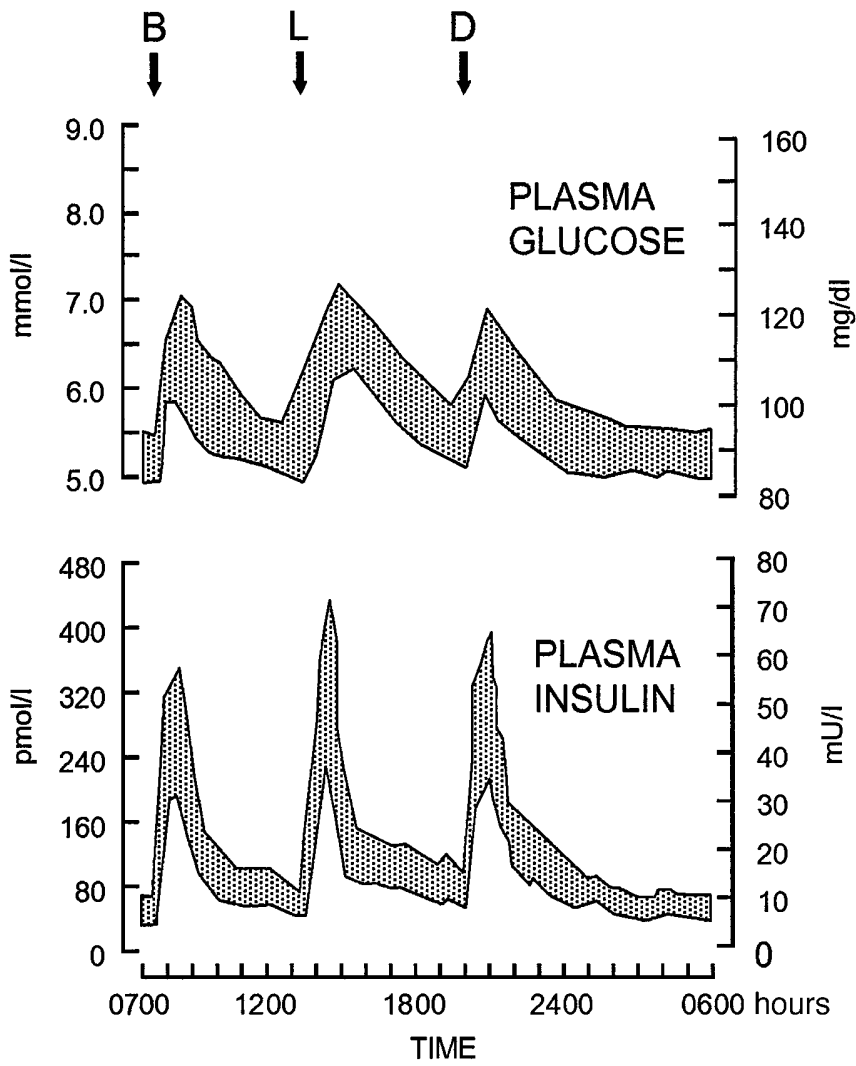

Fig.1. Glucose and insulin homeostasis in normal, non-diabetic people $(n=8)$. Means $\pm 2 \mathrm{SD}$ (Adapted from reference 11). $B=$ Breakfast, $L=$ Lunch, $D=$ Dinner

ified insulins. Biotechnology opened a new area of research with the introduction of insulin analogues in the late 1980s [16] and it soon became apparent that the modified insulins were not just new insulins but new chemical entities. One amino acid modification could lead to changes in the tridimensional structure of the insulin molecule and to major alterations in its biological properties [17]. The fact that insulin in concentrated neutral solution associates into dimers and hexamers [18] and the observation of a lag-phase in the s.c. absorption of soluble insulins $[19,20]$ gave rise to the hypothesis that reduced propensity to self-association might lead to faster absorption of the insulin and shorter duration of action [16]. The approaches used in the creation of monomeric insulin analogues were charge repulsion (AspB28; AspB9,GluB27; GluB28,AspA21), decreased interface hydrophobicity (GluB16,GluB27) and interference with hydrophobic contacts and beta-sheet formation (LysB28,ProB29) [16, 21, 22].

The studies using techniques like circular dichroism spectroscopy [23], osmometry [16], ultracentrifugation [23] and size-exclusion chromatography [23] have shown that the insulin analogues AspB28 (insulin aspart) and LysB28, ProB29 (insulin lispro) have a decreased tendency to self-associate at concentrations existing in therapeutic situations. The addition of zinc to both analogues has not been shown to give a different rate of absorption or time action profile [24, 25]. Common characteristics for these insulins are faster peak plasma insulin concentration and shorter duration of action than human insulin [25-28].

Different in vitro and in vivo biological activities of the new analogues compared with existing insulin of animal origin or human bioengineered insulin immediately called for full toxi- cological and stability testing. Some of the insulin analogues were found to differ substantially in in vitro potency, i.e. in a free-fat cell bioassay and in a culture of HepG2 cells, as a model of adult human liver cells with IGF-I receptors still present [17]. The increased binding of one of these analogues (AspB10) to the IGF-I receptor and a finding suggesting a higher induction of mammary gland tumours when very high concentrations were given to a sensitive female rat strain (the Sprague Dawley rat) raised some concern [29, 30].

\section{Insulin lispro (LysB28, ProB29-human insulin)}

Structure and physicochemical characterstics. Insulin is a heterodimer consisting of an A-chain with 21 amino acids and a B-chain with 30 amino acids. An important clue for the modification that led to insulin lispro was inspired from work with insulin-like growth factor-I (IGF-I) [31]. This hormone does not self-associate even though it is highly homologous with insulin, particularly in the critical C-terminal region of the B-chain. Approximately $50 \%$ of the residues within the A-domain and B-domain of IGF-I are the same as in the A-chain and B-chain of insulin, even including the same disulphide configuration typical of the insulin superfamily. The normally occurring Pro-Lys sequence in insulin at positions B28 and B29 [23, 32] is reversed in IGF-I (i.e., Lys-Pro). The hypothesis was raised that if this Lys-Pro sequence renders IGF-I incapable of self-association, the inversion of the Pro-Lys sequence in insulin would generate an insulin analogue also incapable of self-association [22]. Subsequently, an important structure-activity study was conducted based on moving proline to position B29 coupled with the systematic substitution of both natural and unnatural amino acids into position B28 [23, 32]. Although more than 50 analogues were prepared in this series, the original one was chosen (i. e. LysB28, ProB29-human insulin) since it fulfilled the following criteria: i) it had identical hypoglycaemic potency to regular human insulin in vivo, ii) it was rapid-acting with a short duration in both dogs and pigs, iii) it had greatly reduced self-association characteristics as shown by analytical ultracentrifugation and iv) it represented a structural modification modelled on a natural hormone.

Insulin lispro is a rapid-acting insulin with a short duration of action due to its weakened propensity to self-associate into dimers. Contrary to the prevailing understanding of monomeric analogues, both regular human insulin and insulin lispro exist in their respective formulations as hexamers that are stabilised with zinc ions and phenolic preservatives to assure 2 years of shelf-life at $4^{\circ} \mathrm{C}$. The insulin lispro formulation differs, however, in that its hexamer complex dissociates into monomeric subunits virtually instantaneously upon injection into the subcutis, resulting in a plasma absorption profile indistinguishable from that of a pure monomeric insulin [33]. 
The physicochemical basis for this propensity to self-associate is constituted by one insulin molecule's high affinity for another as directed by key amino acid residues in the C-terminus of each B-chain interacting by hydrogen bonds and aligning in an anti-parallel fashion. Three dimers aggregate into a hexameric unit that is stabilized by coordination to two zinc ions. This is the general molecular arrangement that exists within pharmaceutical insulin formulations. Similarly, zinc ions also appear to play a part in the maturation and storage of microcrystalline insulin within the pancreatic beta-cell granules [15]. A soluble insulin formulation injected at a commercial concentration (e.g. $100 \mathrm{U} / \mathrm{ml}$ or $3.5 \mathrm{mg} / \mathrm{ml}$ ) must undergo more than a 1000-fold dilution in the subcutis to attain a predominantly monomeric state as predicted experimentally using sedimentation equilibrium and light scattering techniques. It is in this form that insulin is recognized by the insulin receptor to deliver a biologic response.

Receptor binding. When compared to regular human insulin in various receptor-binding and cell-based functional assays, insulin lispro was found to be either equipotent or slightly less potent than regular human insulin in binding to the human insulin receptor and slightly more potent than regular human insulin in binding to the human IGF-I receptor [32].

Experiments have also been conducted to determine the dissociation kinetics of ${ }^{125} \mathrm{I}$-human insulin, ${ }^{125} \mathrm{I}$-insulin lispro, and ${ }^{125} \mathrm{I}$-AspB10 from HepG2 cells, a minimal deviation human hepatoma cell line that expresses a high concentration of insulin receptor on its surface. The dissociation rate of insulin lispro from the insulin receptor was equal to that of native insulin whereas the dissociation rate for AspB10 was approximately $50 \%$ of regular human insulin and insulin lispro [32]. This is consistent with higher affinity for the insulin receptor of AspB10 [17, 30].

In other studies, insulin lispro and regular human insulin were compared as to stimulation of glucose and amino acid transport and activation of the insulin signalling pathways in L6 skeletal muscle cells [34]. These studies showed that insulin lispro was equipotent to regular human insulin at stimulating metabolic processes such as glucose and amino acid transport and at activating different arms of the insulin signalling pathway, namely the PI3-kinase/p70 S6 kinase and the ERK signalling cascades.

Toxicology. Acute, subchronic and chronic toxicology studies were conducted on insulin lispro using both rats and dogs. No observations were made that would preclude the long-term use of insulin lispro in people with diabetes [35]. Nor was there any evidence for toxic effects during reproductive or development periods in the rat [36]. Immunogenicity was evaluated in a 1-year rat study in which no evidence of neutral-

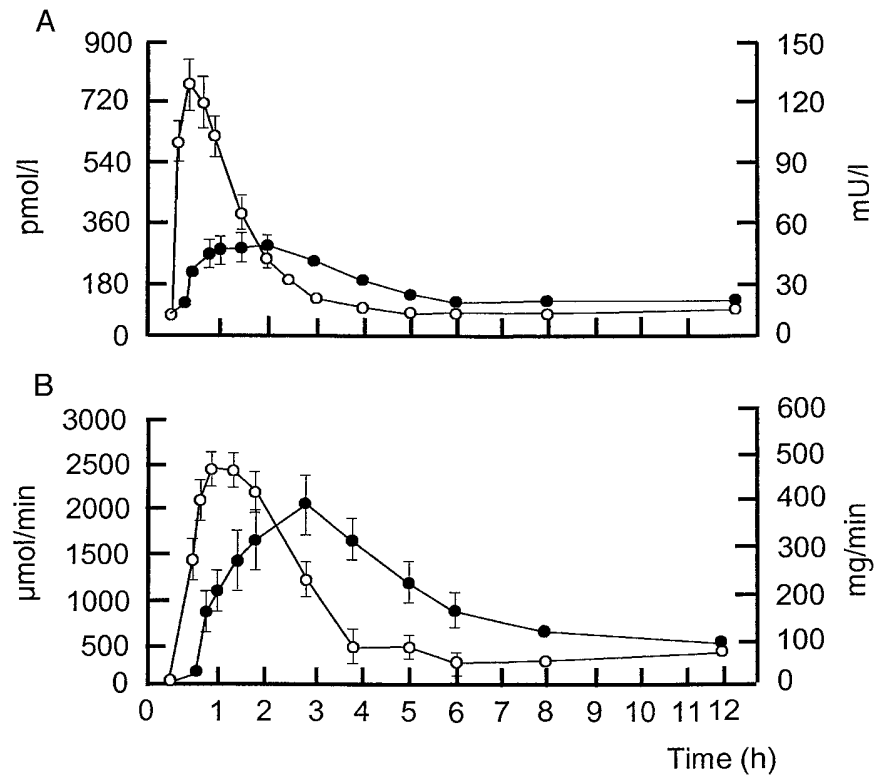

Fig. 2 A, B. Serum insulin concentrations (A) and glucose infusion rates (B) during euglycaemic clamp after s. c. injection of lispro and regular human insulin. $\bigcirc$ Insulin lispro $>$ Regular human insulin. (Adapted from reference 25)

izing antibodies was observed. The observations support the conclusion of extremely weak immunological potential [37].

Pharmacokinetics and dynamics. After a s.c. injection of insulin lispro, serum insulin concentration peaks two times higher and in less than one-half of the time compared with an equal dose of regular human insulin (Fig. 2) [25]. This leads to three differences in the pharmacokinetic and dynamic profile of insulin lispro compared with human insulin: the action begins faster, the peak is higher and disappears faster. Thus, insulin lispro has a more precise action profile at mealtimes with a peak approximately $1 \mathrm{~h}$ after the injection and the effect practically vanishes $4 \mathrm{~h}$ after the injection (Fig. 2) [25]. After intravenous injection, the pharmacokinetics and dynamics are identical with insulin lispro and regular human insulin.

Mealtime control. The effect of insulin lispro on mealtime glycaemic control was initially studied in large multicentre trials in over 2000 adult patients with Type I or Type II (non-insulin-dependent) diabetes mellitus and 500 diabetic adolescents. The studies were done either in a parallel or a cross-over manner for 6 to 12 months. The postprandial rise in plasma glucose was 1.5 to $2.5 \mathrm{mmol} / \mathrm{l}$ lower during insulin lispro than regular human insulin therapy, similarly in Type I and Type II diabetic patients [38-40]. Lower postprandial rise in plasma glucose has been observed consistently in a number of later smaller trials including different treatment strategies [41-43] and can be maintained long-term [44]. 
When insulin lispro was injected $15 \mathrm{~min}$ after the start of a meal, the postprandial rise in plasma glucose was similar to the response when regular human insulin was injected immediately or $20 \mathrm{~min}$ before the meal [45].

Incidental hyperglycaemia. Incidental hyperglycaemia may occur between meals due to dietary errors or for other reasons which often remain unknown. Hyperglycaemia can be symptomatic or detected by glucose self-monitoring. Patients receiving multiple injection therapy often wish to correct incidental hyperglycaemia by taking a small additional dose (2-4 $\mathrm{U})$ of short-acting insulin. The correction of incidental hyperglycaemia or hyperglycaemia during acute illness (sick day) can be done more effectively with a short-acting analogue than with regular human [46-48].

Long-term control. In large multicentre trials in which Type I diabetic patients were transferred from regular human insulin to insulin lispro without any adjustment of basal insulin doses, long-term control as reflected by the $\mathrm{HbA}_{1 \mathrm{c}}$ value remained unchanged [38-40]. The advantage of a better postprandial control with a short-acting analogue was probably counterbalanced by the increase in blood glucose before the next meal or in the morning if no adjustments in the diet or basal insulin regimen were done $[49,50]$. In fact, addition of NPH (30\% of the mealtime dose of lispro insulin) to insulin lispro (henceforth referred to as lispro), but not to regular human insulin, maintains the lower early postprandial blood glucose until late afternoon hours [49]. If NPH is not added to mealtime lispro, particularly at lunch, the increase in pre-prandial blood glucose can deteriorate longterm control [11, 51].

In patients on lispro before meals and split evening insulin, fasting glucose as well as postprandial evening glucose can be greatly improved by transferring the basal insulin injection with increased dose $(+25 \%)$ to late evening and by reducing the pre-dinner lispro dose $(-20 \%)$ [52]. Similarly, reducing prelunch lispro $(-30 \%)$ with supplemental lunchtime NPH maintains the improved postprandial blood glucose control with no deterioration in interprandial control even up to a late dinner [53]. In both of these studies $[52,53]$ the beneficial effects of lispro on postprandial blood glucose were, however, overestimated because the comparison was with regular human insulin given at mealtime (not $30 \mathrm{~min}$ before meals) which deteriorates blood glucose control short-term [10] and long-term [51].

A number of studies have been done to synchronize optimisation of basal insulin and pre-meal insulin therapy taking into account the specific pharmacokinetic characteristics of insulin lipro. Studies have used multiple injection therapy $[11,51,54-57]$ or con- tinuous subcutaneous insulin infusion (CSII) [41, 42, 58]. There has been a consistent improvement in $\mathrm{HbA}_{1 \mathrm{c}}$ of $0.3-0.5 \%$ points compared with the use of regular human insulin even when the latter was appropriately injected $30 \mathrm{~min}$ before meals (Table 1 ). This improvement in long-term control has been achieved without an increase in hypoglycaemia rate. Similar findings have been reported in 950 young patients with Type I diabetes transferred from human regular to lispro insulin at mealtime [59].

The improvement in $\mathrm{HbA}_{1 \mathrm{c}}$ with insulin lispro is not a big one. Analysis of DCCT data indicate, however, that a $10 \%$ improvement in $\mathrm{HbA}_{1 \mathrm{c}}$ at the level of $8 \%$ (from 8.0 to $7.2 \%$ or a $0.8 \%$ point decline) reduces the relative risk of microvascular complications from 25 to $53 \%$ depending on the complication [60].

Mild hypoglycaemia. In one [57] out of six studies [11, 51, 54-57] using similar treatment strategies of Type I diabetes mellitus, the hypoglycaemia rate has been lower during treatment with insulin lispro than with regular human insulin $[39,61]$. In a large study with over 1000 Type I diabetic patients and a statistical power high enough to detect changes in hypoglycaemia, the rate of hypoglycaemia was $12 \%$ less during treatment with insulin lispro. The largest relative difference was observed at night. The difference in the frequency of hypoglycaemia was independent of changes in the $\mathrm{HbA}_{1 \mathrm{c}}$ and of the type and number of basal insulin injections [39]. If the meal has a high fat, low carbohydrate content, there is a greater possibility for early postprandial hypoglycaemia with insulin lispro than with regular human insulin [62]. With such meals the dose of insulin lispro should be smaller than with human insulin. The autonomic responses and hormonal counterregulation to hypoglycaemia induced by lispro and regular human insulin are similar in short-term experiments in Type I diabetic patients $[63,64]$ but possibly improve with lispro long-term [57] as result of less frequent, recurrent hypglycaemia [65]. This can be observed with individualised mixtures of lispro and NPH [57] but not with 75/25 premixed formulation lispro/NPL [66]. With lispro, hypoglycaemia occurs more commonly 90 min after meals compared with regular human insulin treatment where hypoglycaemia more often occurs late after injection [57]. If the dose of regular human insulin is increased to match the postprandial and long-term control obtained with insulin lispro, there is an increase in hypoglycaemia rate; also, the hypoglycaemia awareness and counterregulation are reduced [51, 57]. Thus, there seems to be a trade off: if the control is equal, hypoglycaemia rate is higher with regular human insulin; if the hypoglycaemia rate is similar, the control is better with insulin lispro [51, 55, 57].

Severe hypoglycaemia. A cumulative meta-analysis of severe hypoglycaemias (defined as coma or requiring 
Table 1. Effects of mealtime lispro treatment in Type I diabetes on $\mathrm{HbA}_{1 \mathrm{c}}$ and frequency of hypoglycaemia compared with regular human insulin [injected either $30 \mathrm{~min}$ before $(-30 \mathrm{~min})$ or at mealtime $(0 \mathrm{~min})$ ], in studies with optimised basal insulin regimen

\begin{tabular}{|c|c|c|c|c|}
\hline Authors reference & No of patients & Design & Change in $\%$ point $\mathrm{HbA}_{1 \mathrm{c}}$ & Hypoglycaemia \\
\hline P.Ebeling et al [54] & 66 & $\begin{array}{l}\text { MDI } \\
\text { Open, uncontrolled } \\
5 \text { months, regular } \\
\text { insulin at }-30 \text { min }\end{array}$ & $\begin{array}{l}\sim-0.8 \\
\text { with lispro } \\
\text { vs baseline }\end{array}$ & unchanged \\
\hline P.-A.Jansson et al [55] & 84 & $\begin{array}{l}\text { MDI } \\
\text { Open } \\
\text { Parallel groups } \\
4 \text { months, regular } \\
\text { insulin at - } 30 \mathrm{~min}\end{array}$ & $\begin{array}{l}\sim+0.30 \\
\text { with human } \\
\text { regular }\end{array}$ & unchanged \\
\hline P.Del Sindaco et al [51] & 69 & $\begin{array}{l}\text { MDI } \\
\text { Cross-over } \\
6 \text { months, regular } \\
\text { insulin at }-30 \text { min }\end{array}$ & $\begin{array}{l}\sim-0.35 \\
\text { with lispro }\end{array}$ & unchanged \\
\hline A. Colombel et al [56] & 25 & Idem as above & $\begin{array}{l}\sim-0.35 \\
\text { with lispro }\end{array}$ & unchanged \\
\hline M. Ciofetta et al [11] & 24 & $\begin{array}{l}\text { MDI } \\
\text { Open } \\
\text { Parallel groups } \\
3 \text { months, regular } \\
\text { insulin at - } 30 \text { min }\end{array}$ & $\begin{array}{l}\sim-0.43 \\
\text { with lispro }\end{array}$ & unchanged \\
\hline B. Zinman et al [41] & 30 & $\begin{array}{l}\text { CSII } \\
\text { Double-blind } \\
\text { Cross-over } \\
6 \text { months, regular } \\
\text { insulin at } 0 \text { min }\end{array}$ & $\begin{array}{l}\sim-0.34 \\
\text { with lispro }\end{array}$ & decreased \\
\hline
\end{tabular}

MDI, multiple daily injection regimen; CSII, continuous subcutaneous insulin infusion

glucagon or intravenous glucose) has been done including 8 large trials of $6-12$ months duration. Of the studies five had cross-over and three parallel design. In total 2576 Type I diabetic patients participated. Among them 2327 were using insulin lispro and 2339 patients regular human insulin with similar treatment strategies in all studies [67]. At least one severe hypoglycaemic episode occurred during insulin lispro therapy in $72(3.1 \%)$ patients and during regular human insulin therapy in $102(4.4 \%)$ patients $(p=0.024)$. The frequency per 100-patient years was 14.2 in the insulin lispro and 18.2 in the regular human insulin groups. Thus, the meta-analysis indicates that the rate of severe hypoglycaemia can be reduced by $20-30 \%$ with insulin lispro. If the definition of severe hypoglycaemia is extended to include conditions requiring external help (the same criteria as in DCCT), an individual study with 199 Type I diabetic patients has shown fewer severe hypoglycaemias with insulin lispro than with human insulin [68]. During insulin lispro therapy the counterregulatory response to hypoglycaemia [57] and hepatic sensitivity to glucagon [69] is enhanced which can potentially decrease the risk of severe hypoglycaemia.

Lipid and lipoprotein metabolism. No differences have been observed in serum lipid and lipoprotein concentrations in patients with Type I diabetes treated with insulin lispro and regular human insulin in large multicentre trials [70]. 
Physical exercise. If the recipient exercises soon (1-2 h) after the injection of a short-acting insulin, plasma insulin concentration during insulin lispro therapy is higher and the fall in blood glucose greater than during human insulin treatment [71]. Later exercise, $(3 \mathrm{~h})$ after the pre-meal insulin injection, results in lower plasma insulin concentration during insulin lispro therapy and the fall in plasma glucose is less than during regular human insulin therapy [71]. Since exercise is usually done later rather than soon after a meal, a short-acting insulin analogue is more suitable than regular human insulin for Type I diabetic patients who exercise. The patient who wishes to exercise soon after insulin lispro injection should reduce the pre-meal dose by $20-30 \%$.

Need for snacks. In retrospective interviews, over $40 \%$ of Type I diabetic patients indicated they had used less snacks during insulin lispro than during human insulin therapy. In a prospective study 141 Type I diabetic patients were advised to transfer at least $50 \%$ of their snack calories to main meals during insulin lispro therapy. Those who followed the instructions $(n=67)$ decreased their $\mathrm{HbA}_{1 \mathrm{c}}$ from $7.91 \%$ to $7.66 \%$ whereas no change was observed in patients who did not comply with the dietary change [72]. The improvement in control was associated with a pronounced decline in hypoglycaemia rate.

Injection site. The site of s.c. insulin injection can contribute to differences in absorption rates and variability in the activity of regular human insulin [73]. A sixway cross-over study done in healthy volunteers tested three sites (abdominal, deltoid and femoral) commonly used for s. c. injections of insulin lispro or regular human insulin [74]. A single injection $(0.2 \mathrm{U} / \mathrm{kg})$ of insulin lispro or regular human insulin was given in one of the three sites on each of six separate visits during this glucose clamp study. Although the amount of insulin absorbed did not differ with injection site, the rate of absorption was slower for both insulins with deltoid and femoral injection. Notable delays in the onset of action were, however, apparent only with regular human insulin. Hence, the duration of action was increased for both insulin lispro and regular human insulin, although the increase was smaller with insulin lispro.

Immunogenicity and adverse effects of insulin lispro. The concentration of insulin antibodies during insulin lispro and human insulin therapy has been similar both in Type I and Type II diabetic patients. This is the case in patients previously treated with insulin or in patients naive to exogenous insulin [75] and treated up to 5.4 years [44]. There have been no differences in type and frequency of adverse events between insulin lispro and regular human insulin treatments.
Insulin lispro in patients with immunologic insulin resistance. Three patients have been described in whom allergy to human insulin or severe insulin resistance caused by insulin antibodies was ameliorated by transferring the therapy to insulin lispro with a continuous subcutaneous insulin infusion [76-78]. In addition, one patient with delayed subcutaneous absorption of human insulin has been successfully treated with insulin lispro [79]. These patients are rare and it is not known what caused their insulin resistance or allergy to human insulin after several years of diabetes and why it was so greatly ameliorated with insulin lispro as the only insulin therapy. It can be hypothesized that a better response is related to a faster absorption rate from the subcutaneous injection site.

Patient preference. When the treatment satisfaction was specifically addressed in an international study of 468 Type I diabetic patients, both treatment satisfaction scores and treatment flexibility scores were much higher for insulin lispro than for regular human insulin [80]. The major reason for the preference is convenience; the injection time immediately before the meal.

Strategies of optimisation of basal insulin with mealtime lispro. Lispro can be used in several models of insulin treatment in Type I diabetes mellitus and combined with a variety of insulin preparations. With CSII, improvement in post-meal blood glucose with lispro results in better long-term control than regular human insulin injected either at mealtime [41] or 30 min before meals [42] because basal insulin is optimally replaced. Regarding the regimen of multiple daily injections, in C-peptide negative Type I diabetic patients, mealtime injection of lispro improves long-term blood glucose control only if NPH is given more frequently than during regular human insulin therapy (Fig. 3) [11, 51, 54-57]. Only a few units of NPH given at breakfast, lunch and dinner are needed to improve pre-prandial and fasting blood glucose $[11,51,54-57]$. The amount of NPH injected at each meal was proportional to the number of hours to the next insulin injection. The beneficial effects of a few units of NPH added to mealtime lispro results in appropriate plasma insulin concentrations between meals [11]. A notable advantage of the multiple, but small doses of NPH, is the low risk for interprandial hypoglycaemia compared with once daily NPH treatment [68] because with the former approach the units delivered on each occassion are fewer, the s.c. insulin depot is lower and consequently absorption less erratic [19]. In the 1-year study, NPH combined with lispro at each meal in variable proportions, has decreased the frequency of mild hypoglycaemia by about $35 \%$, improved awareness of, and counterregulation to, hypoglycaemia while HbA1c decreased more than after mealtime human regular insulin [57]. 


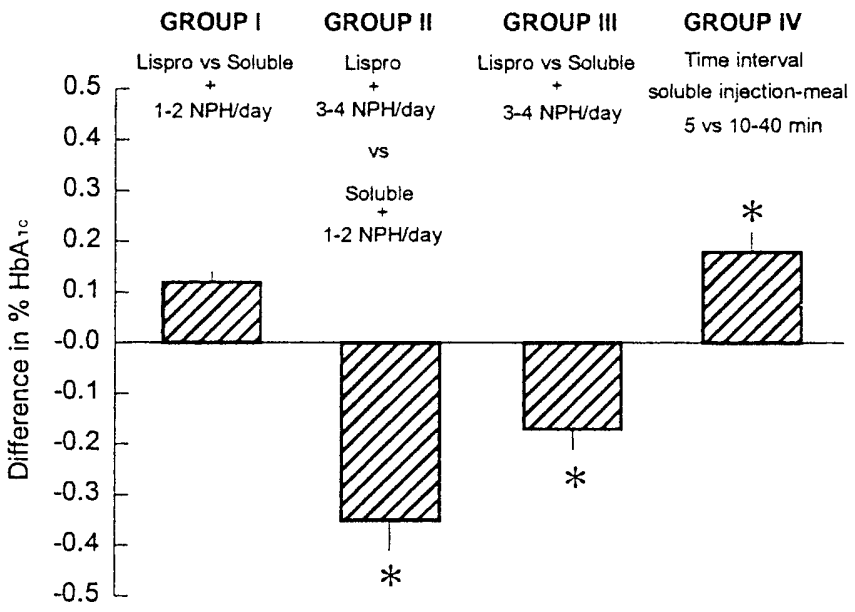

Fig.3. Variations in $\mathrm{HbA}_{1 \mathrm{c}}$ (expressed as percentage point) when mealtime lispro substituted regular human insulin under a variety of possible uses of NPH and timing of injection of regular human insulin. In Group I, $\mathrm{HbA}_{1 \mathrm{c}}$ increased when lispro substituted human regular insulin injected $30 \mathrm{~min}$ before meals with unchanged number of daily NPH injections (1 or 2). In Group II, $\mathrm{HbA}_{1 \mathrm{c}}$ decreased when mealtime lispro was combined with 3-4 daily NPH injections. In Group III, $\mathrm{HbA}_{1 \mathrm{c}}$ also decreased when mealtime lispro substituted regular human insulin 30 min before meals and 3-4 daily NPH injections were used in both regimens. In Group IV, $\mathrm{HbA}_{1 \mathrm{c}}$ increased when regular human insulin was given at mealtime compared with 30 min before. ( $p<0.05$ from reference 51 , with permission)

From a practical point of view, lispro and NPH (or Ultralente) can be mixed in the syringe without any change in the pharmacokinetics of the short-acting component $[81,82]$ but a majority of patients prefer to keep using the pen devices therefore doubling the number of insulin injections at each meal (one for lispro, one for NPH). There are, however, no data to suggest that use of Ultralente with mealtime lispro is at least as good as NPH $[11,51,54-57,83]$. The pharmacokinetic principles predict greater variability in absorption with Ultralente compared to NPH, especially if a large dose is given once or twice daily [19].

A notable exception to the need for multiple daily $\mathrm{NPH}$ doses with mealtime lispro is new-onset Type I diabetes, a condition where residual endogenous insulin secretion can be sufficient to optimize interprandial blood glucose, at least during the day [84].

Lispro in children with Type I diabetes mellitus. The better postprandial glycaemic control after a carbohydrate-rich meal with lispro compared with regular human insulin [85], as well as the more convenient mealtime or postprandial injection, make use of lispro attractive in children $[86,87]$. Type I diabetic children, however, lose residual endogenous insulin secretion faster than adult patients [88]. In totally Cpeptide negative diabetic children, replacement of basal insulin should be optimised when lispro is given at mealtime as in adults [11, 51, 54-57]. At present, this can be done by adding a few units of NPH to lispro at each meal, if the time interval for the next meal is greater than $4 \mathrm{~h}[11,51,54-57]$. The availability of premixed formulations of lispro and its protamine-retarded preparation (NPL) may simplify the present double insulin injection at mealtime.

Lispro during pregnancy. There is no evidence of any differences in safety of insulin lispro in pregnant diabetic patients compared with regular human insulin although controlled prospective studies in pregnant patients are not available. In patients with gestational diabetes, no adverse maternal or fetal outcomes were noted in the patients treated with insulin lispro compared with those who received regular human insulin $[89,90]$. The concern that lispro itself might play a part in the development of proliferative diabetic retinopathy during pregnancy [91] is not justified [92].

Lispro in the management of Type II diabetes mellitus. Mealtime lispro has been compared with regular human insulin injected 30-45 min before meals in 722 Type II diabetic patients (6-month, randomised trial with open, cross-over design)[40]. The prandial plasma glucose was lower $(30 \%$ at $1 \mathrm{~h}, 53 \%$ at $2 \mathrm{~h})$, although no statistically significant change in $\mathrm{HbA}_{1 \mathrm{c}}$ was apparent. It is possible that this occurred because mealtime lispro improves the postprandial blood glucose control only up to $4 \mathrm{~h}$ compared with mealtime regular human insulin which has a longer effect [93]. Clearly, optimisation of basal, inter-prandial insulin, in addition to improved prandial insulin dynamics, would be needed to improve $\mathrm{HbA}_{1 \mathrm{c}}$. Nevertheless, in that study [40] the use of lispro was associated with a lower rate of both total and nocturnal hypoglycaemia episodes ( $p<0.01$ vs regular human insulin). When insulin lispro was added to antecedent treatment with sulphonylurea in Type II diabetic patients, there was a statistically significant decrease in fasting and postprandial glucose concentrations, $\mathrm{HbA}_{1 \mathrm{c}}$ values and serum triglyceride concentrations and a rise in HDL-cholesterol concentrations [94]. No comparison with regular human insulin was, however, made in that study.

When the early rise in plasma insulin was restored with insulin lispro, the plasma glucose profile was ameliorated and late hyperglycaemia and hyperinsulinemia avoided after an oral glucose load compared with the use of regular human insulin [95]. The better postprandial glycaemia was due to a greater suppression of hepatic glucose production with no difference in peripheral glucose disposal. 


\section{Insulin aspart}

Structure. Insulin aspart (NovoRapid) is created by rDNA technology by replacing proline at position B28 in the insulin molecule by the negatively charged aspartic acid. The degree of the self-association decreases similarly to that seen with insulin lispro. Soon after injection a fast dissociation of the analogue to monomers and dimers takes place. The absorption rate of insulin aspart is not statistically significantly different from a purely monomeric analogue such as AspB9, GluB27 [96].

Physicochemical characteristics. The B28 Asp replacement only leads to small local conformational changes in the C-terminus of the B-chain and has little effect on the overall conformation. It has been suggested that rather than inhibiting the formation of dimers by charge repulsion from GluB21, AspB28 replacement removes an important contact between ProB28 and GlyB23 at the monomer-monomer interface [97]. The charge repulsion can contribute to the rapid dissociation into monomers soon after the s.c. injection of the analogue.

Potency. Insulin aspart has an identical potency in vivo on a molar basis compared with human as well as the classical insulin of animal origin when tested in animals [27] and humans [98].

Receptor binding. The receptor binding and kinase activation by insulin aspart has been studied using intact human hepatoma cells (HepG2] and solubilised receptors from these cells. The binding affinity of insulin aspart was $92 \%$ relative to human insulin in HepG2 cells, whereas the analogue B10 had a $327 \%$ affinity [99]. The affinity for the IGF-I receptor by insulin aspart was similar to that of human insulin $[17,30]$.

Toxicology and immunogenicity. Toxicology studies have been done in mice, rats and dogs and have consisted of single-dose, repeated-dose, and 52-week, multiple-dose studies in rats and have not shown differences between human insulin and insulin aspart. The mitogenicity of insulin aspart does not differ from that of human insulin if the ability is tested to stimulate ${ }^{3} \mathrm{H}$ thymidine incorporation into DNA in CHO-K1 cells [100] or the reproduction or mutagenicity in rat aortic smooth muscle cells as well as in mouse NIH 373 fibroblasts.

The formation of insulin antibodies was not different from human insulin $[100,101]$.

Pharmacokinetics and dynamics. The time-action profile of insulin aspart has been assessed in a euglycaemic glucose clamp study in healthy volunteers [102] and by $8 \mathrm{~h}$ profiles in a double-blind crossover study in 25 fasting volunteers receiving a s. c. dose of
$0.1 \mathrm{U} / \mathrm{kg}$ body weight human insulin vs insulin aspart [103]. The absorption of insulin aspart was on average more than twice as fast and reached levels more than twice as high compared with human insulin (maximum plasma insulin concentration of $52 \pm 23$ vs $145 \pm 93$ min, $p<0.0001$ (mean $\pm \mathrm{SD}$ ). The total bioavailability did not differ between the insulins but the mean residence time was shorter for the insulin aspart $(149 \pm 26 \mathrm{~min})$ than for human insulin $(217 \pm 30 \mathrm{~min})(p<0.0001)$ [103].

In a glucose clamp study in healthy volunteers the variability of metabolic effects of insulin aspart was less than that of human insulin as indicated by the pharmacokinetic measures of intra- and interindividual variability [104].

In a double-blind, double-dummy, cross-over trial in patients with Type I diabetes, the post prandial glucose control after a test meal was compared between insulin aspart and regular human insulin over $6 \mathrm{~h}$ [105]. The analogue was given at mealtime and the regular insulin $30 \mathrm{~min}$ before and at mealtime. The maximum concentration of the analogue was reached in half the time, $40 \mathrm{~min}$ (range 30-40 min) vs $97.5 \mathrm{~min}$ (range 50-70 $\mathrm{min}$ ) and $80 \mathrm{~min}$ (range 30$120 \mathrm{~min})(p<0.0001)$ with the two injections of regular insulin measured from the time of injection. The peak concentration was twice as high $(493 \pm 257$ vs $215 \pm 121$ and $239 \pm 131 \mathrm{pmol} / \mathrm{l})$ as compared with human regular insulin. The primary end point, defined as the baseline-corrected excursion of serum glucose from time 0-240 min, showed statistically significant better control with the analogue (891 \pm $\left.521 \mathrm{mmol} \cdot \mathrm{l}^{-1} \cdot \mathrm{min}^{-1}\right)$ as compared with human insulin $\left(\mathrm{t}=0 \mathrm{~min}, 1,311 \pm 512 \mathrm{mmol} \cdot \mathrm{l}^{-1} \cdot \min ^{-1}, \mathrm{t}=\right.$ $\left.230 \mathrm{~min}, 1,106 \pm 571 \mathrm{mmol} \cdot \mathrm{l}^{-1} \cdot \mathrm{min}^{-1}\right) ;(p<0.0001$ and $p<0.02$, respectively). The conclusion of this study was that insulin aspart improved post-prandial glucose control compared with regular human insulin given at the meal and 30 min prior to meal.

Clinical studies with insulin aspart. Insulin aspart was tested in a multicentre, randomised, double-blind, cross-over trial in 90 well-controlled Type I diabetic patients on multiple injection taking one injection of NPH at bedtime and regular insulin at mealtimes [106]. Patients were selected at random for treatment with insulin aspart or regular human insulin both given at mealtime and studied for 1 month. A statistically significant improvement was seen in the postprandial glucose control with insulin aspart $(\sim 1.5 \mathrm{mmol} / \mathrm{l})$ (Fig.4). The Cmax of glucose differed significantly $(p<0.0001)$ between insulin aspart and human insulin following breakfast and lunch during the $24 \mathrm{~h}$ in-patient profile of glucose. After 1 month, however, serum fructosamine did not improve and the study period was too short to measure $\mathrm{HbA}_{1 \mathrm{c}}$. When the 24-h blood glucose was determined in standardised conditions (inpatient unit) with a short time interval between 


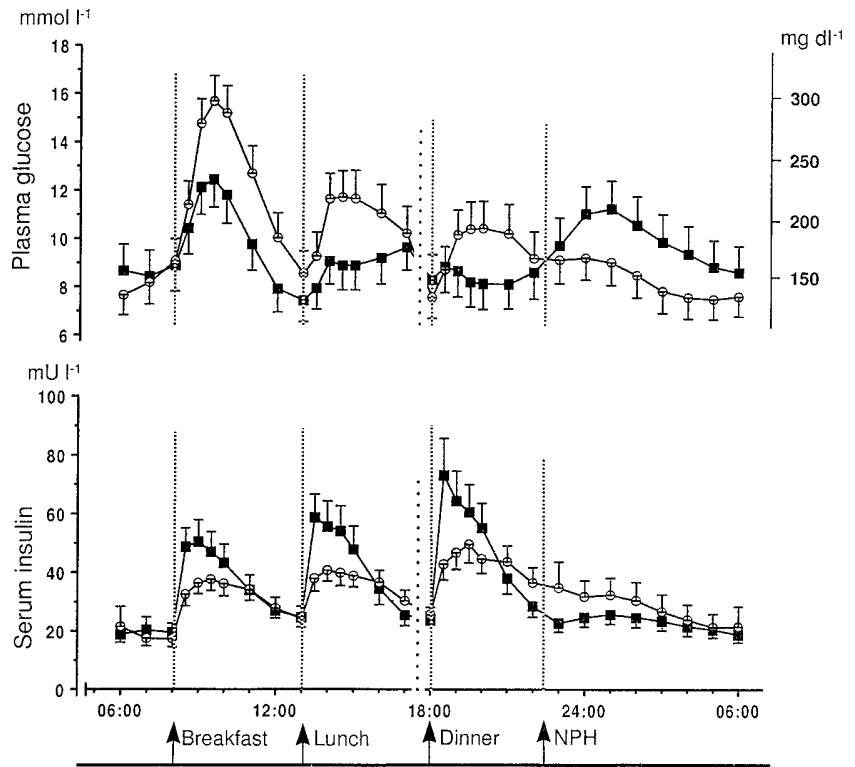

Fig. 4. Serum insulin and plasma glucose profiles in Type I diabetic patients using insulin aspart ( $\square$ ) or regular human insulin (O) before meals. (From reference 106, with permission). In these double-blind studies, human regular and aspart insulins were both injected at mealtime

lunch and dinner, similar pre-lunch, pre-dinner and bedtime glucose concentrations were observed with one single NPH bedtime injection. After 1 month serum fructosamine did not, however, improve. There was no difference in minor hypoglycaemic episodes between the aspart insulin and regular human insulin period. There were, however, fewer episodes of severe hypoglycaemia requiring external assistance in the aspart insulin period compared with the regular human insulin period ( 20 events in 16 patients vs 44 events in 24 patients, $p<0.002$ ). During the last 2 weeks of the study period a $50 \%$ reduction in the number of severe hypoglycaemic events was seen in the aspart insulin group (11 vs 22 events, $p<0.05)$.

In a 6-month study with insulin aspart $(n=707)$ at mealtime or regular human insulin $(n=358)$ dosed 30 min before meals with only once or twice daily basal NPH insulin, $\mathrm{HbA}_{1 \mathrm{c}}$ decreased by $0.12 \%$ point more with insulin aspart than with regular human insulin $(p<0.02)[107]$.

These results are similar to those previously observed with AspB10 [108] and lispro [109] in the absence of optimisation of basal insulin. They suggest that both aspart [106, 107] and lispro [51] insulin analogues could need optimised combination with basal insulin (i.e. more than just the usual once or twice daily NPH) to improve long-term glycaemic control in both Type I [51, 105, 106] and Type II [93, 110, 111] diabetic patients. Aspart, like lispro, can be safely mixed with NPH insulin for immediate s.c. injection [112].

\section{Advantages and disadvantages of short-acting analogues}

The advantages of lispro, compared with regular human insulin, in the management of Type I diabetes are lower 1-h and 2-h post-meal blood glucose (which might reduce the risk for oxidative stress [113]) and, if replacement of basal insulin is optimised, lower $\mathrm{HbA}_{1 \mathrm{c}}[11,51,54-57]$, less frequent hypoglycaemia, better awareness of, and counterregulation to, hypoglycaemia [57]. That the latter result has been reported with individualised lispro/NPH mixtures (not with premixed 75/25 lispro/NPL formulation [66]) indicates that individualised (not fixed lispro/NPH) mixtures are needed to improve long-term blood glucose control.

The importance of preventing and reversing hypoglycaemia unawareness has recently been emphasised [65]. In addition, one important advantage is the more flexible lifestyle because patients can not only inject immediately before the meal but also better adapt the dose to the carbohydrate load [80]. The greatest improvement in long-term blood glucose control with mealtime lispro or aspart can be appreciated in those many patients with Type I diabetes who inject regular human insulin at mealtime with no time interval between injection and meal ingestion [51]. This is also the case in Type II diabetes [93,111]. It is likely that similar advantages will shortly be shown also with future insulin analogues with pharmacokinetic and dynamic properties similar to lispro and aspart insulin.

There has been some concern that an accidental interruption of continuous subcutaneous infusion of insulin in patients treated with CSII would result in a more rapid decompensation if insulin analogue rather than human insulin is used in the pump. In an initial, unpaired study, this was not the case, after night-time interruption [47]. In a more recent, paired study, a 5-h interruption of CSII in daytime resulted, however, in $4.0 \mathrm{mmol} / \mathrm{l}$ greater plasma glucose (and greater non-esterified fatty acid and ketone body) concentration with lispro than with regular human insulin. This was a consequence of a more rapid decrease in plasma insulin concentration with lispro [48]. As in all new medications the price is higher than that of human insulin. In addition, in most of the patients there is a need for 1-2 more daily basal insulin injections.

\section{Long-acting insulin analogues}

Substitution of basal insulin is particularly difficult during the nocturnal hours. Patients with Type I diabetes have variable insulin requirements at night, i.e. less need for insulin between midnight and approximately 0300 hours and about $30 \%$ greater insu- 
lin requirements between 0400 and 0700 hours [114], primarily because of decreased insulin sensitivity in the liver [115]. An ideal long-acting insulin preparation injected s.c. should therefore provide variable insulin delivery, i.e. less insulin in the first than second part of the night. This is feasible with CSII at variable rate [116].

The available intermediate-acting and long-acting insulin preparations for s.c. injection, i.e. NPH (and NPL), Ultralente and a mixture of $30 \%$ Semilente and $70 \%$ Ultralente (Lente), have three major pharmacokinetic and pharmacodynamic defects. Firstly, in contrast to the physiological needs, NPH and Lente show an activity profile with an early peak $4-5 \mathrm{~h}$ after the s.c. injection [117]. Secondly, 5-6 h after the peak, there is a rapid waning of action [117]. These activity profiles of intermediate-acting insulin contribute to problems of nocturnal blood glucose control in Type I diabetes. Thus, after the evening injection of NPH or Lente, plasma insulin peaks approximately between midnight and 0200 hours, i.e. at the time at which patients would require less insulin because they are more insulin sensitive. This contributes to the frequent hypoglycaemia in the early night hours in Type I diabetes despite the bedtime snack [117]. On the other hand, when Type I diabetic patients require an increase in plasma insulin to meet the greater hepatic insulin requirements at dawn [114], the waning of the s.c. injected, intermediate-acting insulin increases systemic glucose production [116] and fasting blood glucose. Because of the "hill-like" action profile of NPH and Lente insulin preparations any attempt to increase plasma insulin bioavailability at dawn simply by increasing the evening dose, increases the risk of nocturnal hypoglycaemia rather than improving nocturnal blood glucose homeostasis [118]. The third pharmacokinetic defect of NPH and Lente is the large variability in the absorption after their s.c. injection [19]. This has to do with the dissolution process of $\mathrm{NPH} /$ Lente insulin crystals in the s.c. tissue into insulin and protamine or zinc. This process is poorly understood and controlled by unknown factors which are ultimately responsible for the variability in absorption [19].

Nocturnal hypoglycaemia occurs in about $30-40 \%$ of Type I diabetic patients $[117,119]$ and causes unawareness of, impaired counterregulation to and adapted cognitive dysfunction during hypoglycaemia the next day [120-122]. Moreover, sleep appears to impair counterregulatory hormone response to hypoglycaemia [123], which even further increases the seriousness of this complication. In turn, hypoglycaemia unawareness predisposes to severe hypoglycaemia [65]. Nocturnal hypoglycaemia can also contribute to fasting and post-meal hyperglycaemia because of the long-lasting post-hypoglycaemic insulin resistance $[124,125]$. Notably, these problems are not due to Type I diabetes itself but to its treatment with surrogate products of basal insulin.

The present candidates for long-acting analogues are being developed based on two principles. The first line of research has been to change the isoelectric point (i.e. the $\mathrm{pH}$ value at which insulin is least soluble and precipitates) towards neutrality by substituting and adding single amino acids to the molecule of human insulin by means of the rDNA technology. The resultant insulin preparation is soluble in acid solution but precipitates as micro-crystals after injection in the subcutaneous tissue where the $\mathrm{pH}$ is neutral [126]. The second principle for protracting a soluble insulin is a modification which promotes the binding to a serum carrier with prolonged half-life, such as albumin [127]. Previously, a soluble, neutral $\mathrm{pH}$, human proinsulin (hPI) formulation was associated with long duration of action and statistically significantly less intrasubject/patient coefficient of variation of response than NPH insulin [128]. The relatively weak insulin agonist activity of human proinsulin dictated, however, in part, against its commercial development. A physiologic conversion intermediate of human proinsulin, namely des(64,65)-hPI, was also evaluated as a soluble, intermediate-acting insulin [129]. Although this drug candidate was fully potent compared with insulin on a molar basis, its duration of action was insufficient when evaluated in patients with Type I diabetes.

\section{Long-acting analogues with neutral isoelectric point}

The first attempt to use this principle of prolongation in diabetic patients was the NovoSol Basal (Novo Nordisk). The development of this insulin preparation was terminated in the second phase owing to local reactions at the injection site and to a study suggesting difficulties in obtaining a constant bioavailability [130].

Insulin glargine: structure and physicochemical characteristics. Insulin glargine (21A-Gly-30Ba-L-Arg30Bb-L-Arg-human insulin) (HOE 901) produced by rDNA technology, is a human insulin analogue with prolonged action. This is the closest long-acting insulin analogue for clinical use. It is expected to come on the market in the year 2000.

Insulin glargine results from two modifications of human insulin. First, two positive charges (two arginine molecules) are added at the C-terminus of the $\mathrm{B}$-chain. This results in a shift of the isoelectric point from a $\mathrm{pH}$ of 5.4 to $6.7 \pm 0.2$ making the molecule more soluble at slightly acidic $\mathrm{pH}$ and less soluble at the physiological $\mathrm{pH}$ of s.c. tissue. Because the derivative is formulated at an acidic $\mathrm{pH}$, a second modification is needed to avoid deamidation and dimerisation by the acid-sensitive asparagine residue 


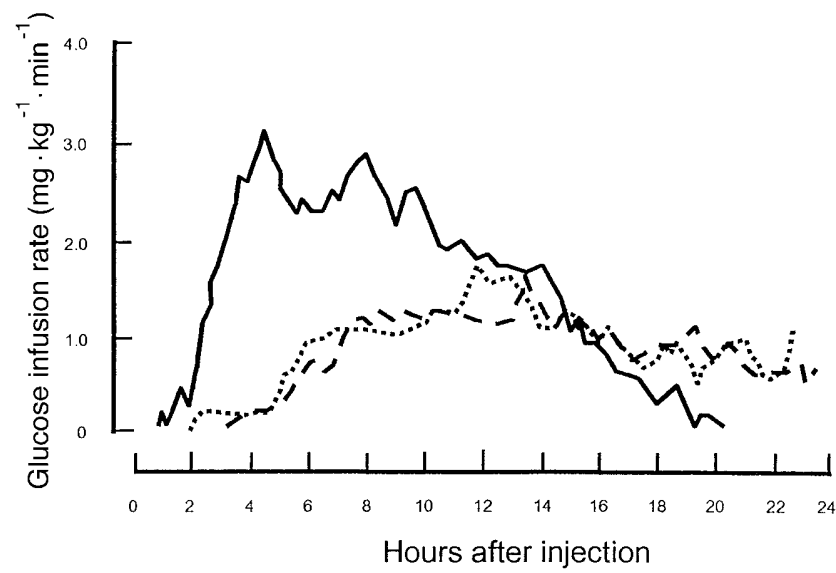

Fig. 5. Median glucose infusion rate after s. c. injection of 0.2 IU/Kg NPH and two formulations of HOE 901 containing 15 and $80 \mu \mathrm{g} / \mathrm{ml}$ zinc, in normal human volunteers assessed by the euglycaemic glucose clamp technique. - - HOE901 [15] ... HOE901[80] - NPH human insulin (Adapted from data from reference 133)

at position 21 in the A-chain. The replacement of A21 asparagine by glycine is charge-neutral and associated with good stability of the resulting human insulin analogue [131]. Injected as a clear solution of $\mathrm{pH} 4.0$, insulin glargine forms a microprecipitate at the physiologic, neutral $\mathrm{pH}$ of the s.c. space. The stabilisation of the insulin hexamer and higher aggregates can influence the nature of the precipitate and the rate of its dissolution and absorption from the site of injection. Consequently, insulin glargine has a delayed and prolonged absorption from the injection site after s.c. injection. The structural changes in the insulin peptide result in an analogue with delayed absorption and a relatively constant basal insulin supply consistent with that secreted by nondiabetic subjects. Because insulin glargine is formulated as a clear, acidic solution, it cannot be mixed with insulin formulated at a neutral $\mathrm{pH}$ such as regular insulin.
Changes in the insulin molecular structure can change the interaction with the insulin receptor and with the structurally homologous insulin-like growth factor-I (IGF-I) receptor. Glargine has different characteristics in vitro but exerts a mitogenic and growth promoting activity essentially identical to human insulin $[131,132]$. Carcinogenicity studies in rats and mice do not indicate a risk for cancer in humans.

Pharmacokinetics and dynamics of insulin glargine. Animal studies as well as clinical studies clearly differentiate the pharmacokinetics and biologic activity profile of insulin glargine from that of NPH [133-135]. Animal studies indicate that the absorption of insulin glargine is zinc-dependent and clinical studies have been designed to test the zinc-dependency of absorption in humans.

Pharmacokinetic studies with two formulations of glargine, HOE 901[15] and HOE 901[80] containing 15 and $80 \mu \mathrm{g} / \mathrm{ml}$ zinc, respectively and with semisynthetic NPH human insulin have been carried out both in healthy subjects (Fig. 5) [133] and Type I diabetic patients [134]. In both studies, glargine activity is peakless and $50 \%$ lower and the duration of activity twofold longer than observed with NPH. There was no difference between the two glargine formulations (Table 2).

The differences in the activity profile of insulin glargine shown by the euglycaemic [133] and isoglycaemic [134] clamp technique are supported by assessment of absorption from the injection site. A randomised, double-blind, three-way cross-over study design was used to compare absorption of two formulations of glargine, HOE 901[15] and HOE 901[80] and NPH human insulin. Each insulin was tagged with ${ }^{125} \mathrm{I}$ and injected s.c. into the abdomen of 12 healthy volunteers. The disappearance of radioactivity from the injection site indicated that NPH insulin was absorbed more quickly than either formulation of glargine with small differences between 15 and $80 \mu \mathrm{g} / \mathrm{ml}$ zinc formulations. Blood glucose profiles with the two glargine

Table 2. Pharmacokinetics and dynamics of s. c. injection of glargine (HOE 901) insulin

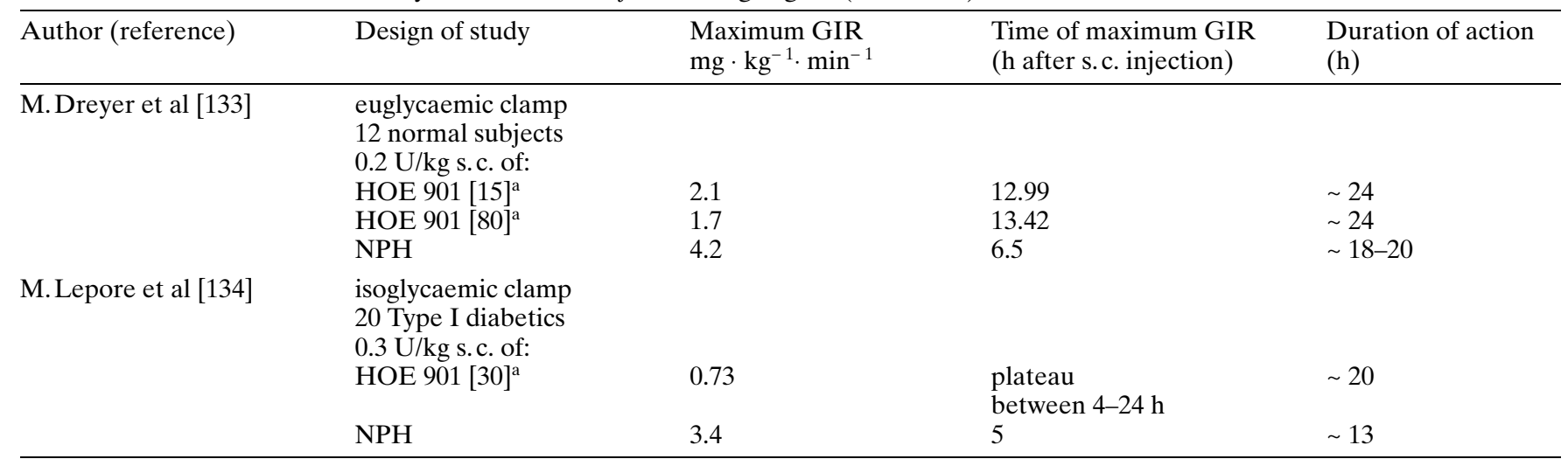

GIR, glucose infusion rate; ${ }^{\text {a }}$ containing 15 or 30 or $80 \mu \mathrm{g} / \mathrm{ml}$ zinc 
formulations were not different but blood glucose concentrations did show a clear difference between glargine and NPH. Similar conclusions have been obtained in an absorption study after s. c. injection of 0.3 $\mathrm{U} / \mathrm{kg}$ radiolabelled insulin in patients with Type II diabetes [135]. In another study, after $0.2 \mathrm{U} / \mathrm{kg}$ injection of ${ }^{125}$ I-labelled glargine into the abdomen, arm or leg in 12 non-diabetic subjects, the absorption rate showed no variation between injection sites in contrast to NPH [136].

Clinical studies on insulin glargine. Twelve patients with C-peptide negative Type I diabetes, previously treated with NPH insulin four times daily plus regular insulin before three main meals, were treated with glargine injected once daily for 4 days at 2200 hours with a dose equivalent to the previous NPH total daily dose [137]. The dose of regular insulin was maintained. The blood glucose profile after the once daily glargine regimen was similar to that with the four times daily NPH regimen.

Further studies have been done in patients with Type I diabetes treated for 4 weeks [138, 139]. The objective of these studies was to evaluate the effectiveness and tolerability of glargine compared with NPH. Effectiveness was assessed with fasting plasma glucose. Glargine given once daily at bedtime reduced fasting plasma glucose statistically significantly more than NPH human insulin given once or twice daily. The improvements in glycaemic control seen with glargine compared with NPH in these 4-week studies were achieved with a lower [138] or similar [139] incidence of nocturnal hypoglycaemia. These results have been confirmed in a 28 -week randomised trial in 534 patients with Type I diabetes on multiple daily insulin injection regimen allocated to bedtime glargine or bedtime NPH or NPH b.i.d. Fasting plasma glucose was approximately $1.3 \mathrm{mmol} / \mathrm{l}$ lower and frequency of hypoglycaemia (blood glucose $<2.0 \mathrm{mmol} / \mathrm{l}$ ) was more than $50 \%$ lower with glargine [140]. Similar results have been observed in a 28-week randomized trial in 518 patients with Type II diabetes [141]. Taken together, these data suggest that the majority of patients with Type I and perhaps also Type II diabetes might benefit from insulin glargine [142].

Immunogenicity of insulin glargine. In animal studies insulin glargine has been less immunogenic than human insulin. Data in humans will be available from results of long-term clinical studies.

\section{Fatty acid acylated insulins}

Another principle for protracting a soluble insulin action is a modification which promotes the binding to serum proteins like albumin. The rationale is that s.c. albumin binding and consequently increased plasma half-life will prolong the action profile. The analogue is created by acylation of the $\varepsilon$-amino group of LysB29 with a saturated fatty acid [143]. The length of the fatty acid attached to the LysB29 has a pronounced effect on the disappearance rate of radiolabelled insulin from the injection site [143]. The highest affinity for albumin and most protracted duration of action was found for LysB29 tetradecanoyldes (B30) insulin (NN304, Novo Nordisk). The absorption tested in a pig model showed that absorption was statistically significantly slower than human NPH [127]. Intravenous bolus injection of this analogue showed a protracted blood glucose lowering effect compared with human NPH insulin. The intraindividual variation of the absorption from day to day was less for NN304 than for NPH [144]. Drugs known to increase the plasma non-esterified fatty acid concentration (heparin, beta-agonists) and drugs in therapeutic concentrations with high affinity for human serum albumin (sulphonylurea, Diazepam, Valproate) did not statistically significantly influence the NN304 albumin binding [145]. Due to the low plasma concentration of NN304, the insulin analogue itself cannot be expected to displace other drugs. Further studies with in vivo testing are, however, needed to evaluate if any clinically meaningful drug concentrations influence the time/action profile of NN304 in humans.

The pharmacokinetics of insulin NN304 was studied in a euglycaemic glucose clamp trial comparing NN304 and NPH in healthy subjects [146]. Treatment with three different doses of NN304 (0.15, 0.3 and 0.6 $\mathrm{U} / \mathrm{kg}$ ) resulted in a proportional increase in the total area under the plasma insulin curve. Compared with NPH, NN304 had a less pronounced peak and maximum concentrations were seen after $4-6 \mathrm{~h}$. The NN304 insulin still, however, had a peak and no clear dose-response relation of NN304 on glucose utilisation was shown.

A second acylated insulin is $\mathrm{N}^{\varepsilon}$-palmitoyl LysB29human insulin (C16-HI, Eli Lilly). The extended time action of C16-HI was shown in diabetic dogs compared with regular human insulin in both i.v. and s.c. experiments [147]. In addition, C16-HI was longer acting and less variable in response compared with Lente insulin when both insulins were given subcutaneously. The $\mathrm{C} 16-\mathrm{HI}$ insulin was also studied in a pig model. Compared with NPH insulin, s.c. injected C16-HI gave a flatter pharmacokinetic and glucodynamic response with a longer duration of action. In both the dog and pig studies the effective biologic potency of C16-HI was less than the respective insulin comparators. Results from a phase I clinical doseranging study with 23 healthy volunteers given C16HI s.c. suggested that the drug's potency was $20-25 \%$ of NPH. In a subsequent clinical pharmacology study in nine patients with Type I diabetes [148, 149] the glucodynamic profile of subcutaneously in- 
jected C16-HI was apparently similar to that of NPH human insulin. The results of these studies are, however, difficult to interpret because in these experiments both insulin and glucose were infused i.v. to clamp plasma glucose. In addition, the apparently similar activity profiles of $\mathrm{C} 16-\mathrm{HI}$ and $\mathrm{NPH}$ were achieved at the expense of the five times greater dose of C16-HI (i.e. $6 \mathrm{nmol} / \mathrm{kg}$ vs $1.2 \mathrm{nmol} / \mathrm{kg}$, the molar equivalent of $1.0 \mathrm{U} / \mathrm{kg}$ vs $0.2 \mathrm{U} / \mathrm{kg}$ ). The relatively high blood concentrations of C16-HI suggested appreciable binding to serum albumin.

These human data validate the premise that interaction with albumin can be used as a means to extend the time action of a fatty acid-acylated insulin derivative, although C16-HI can bind too avidly leading to a relatively low overall bioeffectiveness. Even though this appears to be a viable approach for a soluble insulin formulation at neutral $\mathrm{pH}$, there is some question about the margin of pharmaceutical elegance due to solubility characteristics of the more lipophilic fatty acyl insulin derivatives, particularly if the concentration of the insulin derivative must be increased appreciably to accommodate a reduced potency. There is reason to believe, however, that such a molecule is possibly at least as conformationally stable as insulin [150]. Clearly, considerable research is still needed to evaluate the relation between the attractive pharmacokinetics and dynamics of acylated human insulin as a candidate to replace basal insulin and its bioavailability in humans.

\section{Premixed short-acting analogue formulations}

To extend its short duration of action while maintaining the early peak after s.c. injection, in practice lispro is often mixed with NPH at meals [11, 51, 54-57]. Stable premixed formulations of lispro and NPL (neutral protamine lispro) in the proportions of 25/75 (low-mix), 50/50 (mid-mix) and 75/25 (highmix) have been developed. Whereas the low-mix and mid-mix have already come on the market, the high-mix is still under evaluation in clinical studies. The NPL insulin has an action profile practically similar to NPH but prolongs the shelf-life of premixed formulations [151]. The pharmacokinetic data of the first premixed insulin analogues in non-diabetic subjects indicate pharmacokinetic and pharmadynamic characteristics different from the corresponding premixed human insulin preparations [152, 153]. The pre-meal use of a premixed lispro formulation (25/75 lispro/NPL) has shown a statistically significantly better postprandial control than 30/70 human regular/ NPH insulin formulation in Type II diabetic patients $[154,155]$. The premixed formulations relevant to the treatment of Type I diabetic patients are the ones with a high proportion of the short-acting analogue, i. e. high-mix and mid-mix (75/25 and 50/50, re- spectively lispro and NPL). It remains, however, to be established whether premixed formulations can successfully substitute the instantly prepared mixtures of lispro and NPH [11, 51, 54-57].

\section{Conclusion}

There are reasonable premises to expect that in the near future the use of short-acting and long-acting insulin analogues will provide better glycaemic control (lower $\mathrm{HbA}_{1 \mathrm{c}}$, less day to day variability in plasma glucose, less hypoglycaemias with preserved awareness of, and counterregulation to, hypoglycaemia) and a freer lifestyle. Although both CSII and multiple daily insulin injections already allow achievement of fair to good glycaemic control, it is expected that with insulin analogues the maintenance of longterm, near-normoglycaemia will be easier, provided that they are appropriately used and implemented in the overall strategy of diabetes care in Type I diabetes. Due to the pharmacokinetic characteristics of insulin analogues, they will provide an insulin profile closer to normal physiology than can be achieved with s. c. injection of human insulin. It is thus possible that the appropriate use of the analogues can improve the metabolic control and lifestyle of both Type I and Type II diabetic patients.

Acknowledgements. The authors thank L. Vignati and S. Del Prato for their precious contribution to and critical comments of this review and are extremely grateful to R. Chance for his invaluable help in carefully reviewing the manuscript and the appropriate use of references.

\section{References}

1. Rizza RA, Gerich JE, Haymond MW et al. (1980) Control of blood sugar in insulin-dependent diabetes:comparison of an artificial endocrine pancreas, continuous subcutaneous insulin infusion, and intensified conventional therapy. N Engl J Med 303: 1313-1318

2. Reichard P, Nilsson B-Y, Rosenqvist U (1993) The effect of long-term intensified insulin treatment on the development of microvascular complications of diabetes mellitus. N Engl J Med 329: 304-309

3. The Diabetes Control and Complications Trial Research Group (1993) The effect of intensive treatment of diabetes on the development and progression of long-term complications in insulin-dependent diabetes mellitus. N Engl J Med 329: 977-986

4. Waldhäusl WK (1986) The physiological basis of insulin treatment. Clinical aspects. Diabetologia 29: 837-849

5. Pampanelli S, Fanelli C, Lalli C et al. (1996) Long-term intensive insulin therapy in IDDM:effects of $\mathrm{HbA} 1 \mathrm{c}$, risk for severe and mild hypoglycaemia, status of counterregulation and awareness of hypoglycaemia. Diabetologia 39: 677-686

6. Fanelli C, Pampanelli S, Epifano L et al. (1994) Long-term recovery from unawareness, deficient counterregulation and lack of cognitive dysfunction during hypoglycaemia, following institution of rational, intensive insulin therapy in IDDM. Diabetologia 37: 1265-1276 
7. Bott S, Bott U, Berger M, Mülhauser I (1997) Intensified insulin therapy and the risk of severe hypoglycaemia. Diabetologia 40: 926-932

8. Mühlhauser I, Overmann H, Bender R, Bott U, Berger M (1998) Risk factors of severe hypoglycaemia in adult patients with Type I diabetes - a prospective population based study. Diabetologia 41: 1274-1282

9. Valle T, Koivisto VA, Reunanen A et al. (1999) Glycemic control in patients with diabetes in Finland. Diabetes Care 22: $575-579$

10. Dimitriadis GD, Gerich JE (1983) Importance of timing of preprandial subcutaneous insulin administration in the management of diabetes mellitus. Diabetes Care 6: 374-377

11. Ciofetta M, Lalli C, Del Sindaco P et al. (1999) Contribution of postprandial versus interprandial blood glucose to $\mathrm{HbA} 1 \mathrm{c}$ in Type I diabetes on physiologic intensive therapy with lispro insulin at mealtime. Diabetes Care 22: 795-800

12. Barnett AH, Owens DR (1997) Insulin analogues. Lancet 349: 47-51

13. Holleman F, Hoekstra JBL (1997) Insulin lispro. N Engl J Med 337: 176-183

14. Lee WL, Zinman B (1998) From insulin to insulin analogs:progress in the treatment of Type I diabetes. Diabetes Rev 6: 73-88

15. Emdin SO, Dodson GG, Cutfield JM, Cutfield SM (1980) Role of zinc in insulin biosynthesis. Some possible zinc-insulin interactions in the pancreatic B-cell. Diabetologia 19: 174-182

16. Brange J, Ribel U, Hansen JF et al. (1988) Monomeric insulins obtained by protein engineering and their medical implications. Nature 333: 679-682

17. Drejer K, Kruse V, Larsen UD et al. (1991) Receptor binding and tyrosine kinase activation by insulin analogues with extreme affinities studied in human hepatoma HepG2 cells. Diabetes 40: 1488-1495

18. Blundell T, Dodson G, Hodgkin D, Mercola D (1972) Insulin:the structure in the crystal and its reflection in chemistry and biology. Adv Protein Chem 26: 279-402

19. Binder C, Lauritzen T, Faber O, Pramming S (1984) Insulin pharmacokinetics. Diabetes Care 7: 188-199

20. Hildebrandt P, Sestoft L, Nielsen SL (1983) The absorption of subcutaneously injected short-acting soluble insulin:influence of injection technique and concentration. Diabetes Care 6: 459-462

21. Brange J, Owens DR, Kang S, Vølund A (1990) Monomeric insulins and their experimental and clinical implications. Diabetes Care 13: 923-954

22. Di Marchi RD, Chance RE, Long HB, Shields JE, Slieker LJ (1994) Preparation of an insulin with improved pharmacokinetics relative to human insulin through consideration of structural homology with insulin-like growth factor I. Horm Res 41[Suppl 2]:S93-S96

23. Brems DN, Alter LA, Beckage MJ et al. (1992) Altering the association properties of insulin by amino acid replacement. Protein Eng 5: 527-533

24. Wiefels K, Kuglin B, Hübinger A, Jorgensen LN, Gries FA (1993) Insulin kinetics and dynamics in insulin-dependent diabetic patients after injections of human insulin or the insulin analogues X14 and X14 + Zn. In: Berger M, Gries FA (eds) Frontiers in Insulin Pharmacology. Thieme, Stuttgart, pp 97-101

25. Howey DC, Bowsher RR, Brunelle RL, Woodworth JR (1994) [Lys(B28),Pro(B29)]-human insulin. A rapidly absorbed analogue of human insulin. Diabetes 43: 396-402

26. Kang S, Brange J, Burch A, Vølund A, Owens DR (1991) Subcutaneous insulin absorption explained by insulin's physicochemical properties. Evidence from absorption studies of soluble human insulin and insulin analogues in humans. Diabetes Care 14: 942-948

27. Vølund A, Brange J, Drejer K et al. (1991) In vitro and in vivo potency of insulin analogues designed for clinical use. Diabet Med 8: 839-847
28. Kang S, Brange J, Burch A, Vølund A, Owens DR (1991) Absorption kinetics and action profiles of subcutaneously administrated insulin analogues (AspB9, GluB27; AspB10; AspB28) in healthy subjects. Diabetes Care 14: 1057-1065

29. Jørgensen LN, Dideriksen LH (1993) Preclinical studies of rapid-acting insulin analogues. In: Berger M, Gries FA (eds) Frontiers in insulin pharmacology. Thieme, Stuttgart, pp 110-117

30. Drejer K (1992) The bioactivity of insulin analogues from in vitro receptor binding to in vivo glucose uptake. Diabetes Metab Rev 8: 259-285

31. Di Marchi R, Long H, Epp J, Schoner B, Belagaje R (1989) Synthesis of insulin-like growth factor I through recombinant DNA techniques and selective chemical cleavage at tryptophan. In: Tam JP, Kaiser ET (eds) Synthetic peptides:approaches to biological problems. Liss, New York, pp 283-294

32. Slieker LJ, Brooke GS, Di Marchi RD et al. (1997) Modifications in the B10 and B26-30 regions of the B chain of human insulin alter affinity for the human IGF-I receptor more than for the insulin receptor. Diabetologia 40[Suppl 2]:S54-S61

33. Radziuk JM, Davies JC, Pye WS et al. (1997) Bioavailability and bioeffectiveness of subcutaneous human insulin and two of its analogs - LysB28,ProB29-human insulin and AspB10, LysB28,ProB29-human insulin - assessed in a conscious pig model. Diabetes 46: 548-556

34. Somwar R, Sweeney G, Ramlal T, Klip A (1998) Stimulation of glucose and amino acid transport and activation of the insulin signaling pathways by insulin lispro in L6 skeletal muscle cells. Clin Ther 20: $125-140$

35. Zimmermann JL, Truex LL (1997) A 12-month chronic toxicity study of LY275585 (human insulin analog) administered subcutaneously to Fischer 344 rats. Int J Toxicol 16: 639-657

36. Buelke-Sam J, Byrd RA, Hoyt JA, Zimmermann JL (1994) A reproductive and developmental toxicity study in $\mathrm{CD}$ rats of LY275585 [Lys(B28,Pro(B29)]-human insulin. J Am Coll Toxicol 13: 247-260

37. Zwickl CM, Smith HW, Zimmermann JL, Wierda D (1995) Immunogenicity of biosynthetic human LysPro insulin compared to native-sequence human and purified porcine insulins in rhesus monkeys immunized over a 6-week period. Arzneimittelforschung 45 (I):524-528

38. Anderson JH Jr, Brunelle RL, Koivisto VA et al. (1997) Improved mealtime treatment of diabetes mellitus using an insulin analogue. Clin Ther 19: 62-72

39. Anderson JH Jr, Brunelle RL, Koivisto VA et al. (1997) Reduction of postprandial hyperglycemia and frequency of hypoglycemia in IDDM patients on insulin-analog treatment. Diabetes 46: 265-270

40. Anderson JH Jr, Brunelle RL, Keohane P et al. (1997) Mealtime treatment with insulin analog improves postprandial hyperglycemia and hypoglycemia in patients with non-insulindependent diabetes mellitus. Arch Int Med 157: 1249-1255

41. Zinman B, Tildesley H, Chiasson J-L, Tsui E, Strack T (1997) Insulin lispro in CSII. Results of a double-blind cross-over study. Diabetes 46: 440-443

42. Melki V, Renard E, Lassmann-Vague V et al. (1998) Improvement of HbA1 $\mathrm{c}$ and blood glucose stability in IDDM patients treated with lispro insulin analog in external pumps. Diabetes Care 21: 977-982

43. De Verga V, Ristic S, and the Ramadan Study Group (1998) Insulin lispro therapy during Ramadan fasting. Diabetes 47[Suppl 1]:A105 (Abstract)

44. Garg SK, Anderson JH, Perry SV et al. (1999) Long-term efficacy of Humalog ${ }^{\circledR}$ in subjects with Type I diabetes mellitus. Diabet Med 16: 384-387

45. Schernthaner G, Wein W, Sandholzer K et al. (1998) Postprandial insulin lispro. A new therapeutic option for Type I diabetic patients. Diabetes Care 21: 570-573

46. Holleman F, van den Brand JJG, Hoven RARA et al. (1996) Comparison of LysB28, ProB29-human insulin analog and 
regular human insulin in the correction of incidental hyperglycemia. Diabetes Care 19: 1426-1429

47. Attia N, Jones TW, Holcombe J, Tamborlane WV (1998) Comparison of human regular and lispro insulins after interruption of continuous subcutaneous insulin infusion and the treatment of acutely decompensated IDDM. Diabetes Care 21: 817-821

48. Guerci B, Meyer L, Sallé A et al. (1999) Comparison of metabolic deterioration beteween insulin analog and regular insulin after a 5-hour interruption of a continuous subcutaneous insulin infusion in Type I diabetic patients. J Clin Endocrinol Metab 84: 2673-2678

49. Torlone E, Pampanelli S, Lalli C et al. (1996) Effects of shortacting insulin analog [Lys(B28),Pro(B29)] on postprandial blood glucose control in IDDM. Diabetes Care 19: 945-952

50. Ahmed ABE, Home PD (1998) The effect of the insulin analog lispro on nighttime blood glucose control in Type I diabetic patients. Diabetes Care 21: 32-37

51. Del Sindaco P, Ciofetta M, Lalli C et al. (1998) Use of the short-acting insulin analogue lispro in intensive treatment of Type I diabetes mellitus:importance of appropriate replacement of basal insulin and time-interval injection-meal. Diabet Med 15: 592-600

52. Ahmed ABE, Mallias J, Home PD (1998) Optimization of evening insulin dose in patients using the short-acting insulin analog lispro. Diabetes Care 21: 1162-1166

53. Ahmed ABE, Home PD (1998) Optimal provision of daytime NPH insulin in patients using the insulin analog lispro. Diabetes Care 21: 1707-1713

54. Ebeling P, Jansson P-A, Smith U et al. (1997) Strategies toward improved control during insulin lispro therapy in IDDM:importance of basal insulin. Diabetes Care 20: 1287-1289

55. Jansson P-A, Ebeling P, Smith U et al. (1998) Improved glycemic control can be better maintained with insulin lispro than with human regular insulin. Diab Nutr Metab 11: 194-199

56. Colombel A, Murat A, Krempf M et al. (1999) Improvement of blood glucose control in Type I diabetic patients treated with lispro and multiple NPH injections. Diabet Med 16: 319-324

57. Lalli C, Ciofetta M, Del Sindaco P et al. (1999) Long-term intensive treatment of Type I diabetes with the short-acting insulin analogue lispro in variable combination with NPH insulin at mealtime. Diabetes Care 22: 468-477

58. Renner R, Pfützner A, Trautmann M et al. (1999) Use of insulin lispro in continuous subcutaneous insulin infusion treatment:results of a multicenter trial. Diabetes Care 22: 784-788

59. Chase HP, Peery BN, Sheperd ME et al. (1999) The impact of the DCCT and of Humalog treatment on glycohemoglobin (HbA1c) and hypoglycemia in Type I diabetes. Diabetes 48[Suppl 1]:A100 (Abstract)

60. The Diabetes Control and Complications Trial Research Group (1996) The absence of a glycemic threshold for the development of long-term complications:the perspective of the Diabetes Control and Complications Trial. Diabetes 45: 1289-1298

61. Pfützner A, Küstner E, Forst T et al. (1996) Intensive insulin therapy with insulin lispro in patients with Type I diabetes reduces the frequency of hypoglycemic episodes. Exp Clin Endocrinol Diabetes 104: 25-30

62. Burge MR, Castillo KR, Schade DS (1997) Meal composition is a determinant of lispro-induced hypoglycemia in IDDM. Diabetes Care 20: 152-155

63. Torlone E, Fanelli C, Rambotti AM et al. (1994) Pharmacokinetics, pharmacodynamics and glucose counterregulation following subcutaneous injection of the monomeric insulin analogue [Lys(B28), Pro(B29)] in IDDM. Diabetologia 37: 713-720

64. McCrimmon RJ, Frier BM (1997) Symptomatic and physiological responses to hypoglycaemia induced by human soluble insulin and the analogue lispro human insulin. Diabet Med 14: 929-936

65. Bolli GB (1997) Hypoglycaemia unawareness. Diabetes Metab 23[Suppl 3]:S29-S35

66. Janssen MMJ, Masurel M, Hoogma RPLM et al. (1998) Effects of multiple injection therapy with lispro high mix insulin on the catecholamine response to hypoglycaemia. Diabetologia 41[Suppl 1]:A244 (Abstract)

67. Brunelle RL, Llewelyn J, Anderson JH Jr, Gale EAM, Koivisto VA (1998) Meta-analysis of the effect of insulin lispro on severe hypoglycemia in patients with Type 1 diabetes. Diabetes Care 21: 1726-1731

68. Holleman F, Schmitt H, Rottiers R et al. (1997) Reduced frequency of severe hypoglycemia and coma in well-controlled IDDM patients treated with insulin lispro. Diabetes Care 20: $1827-1832$

69. Launay B, Zinman B, Tildesley HD, Strack T, Chiasson J-L (1998) Effect of continuous subcutaneous insulin infusion with lispro on hepatic responsiveness to glucagon in type 1 diabetes. Diabetes Care 21: 1627-1631

70. Anderson JH Jr, Koivisto VA (1998) Clinical studies on insulin lispro. Drugs of Today 34[Suppl C]:37-50

71. Tuominen JA, Karonen S-L, Melamies L, Bolli G, Koivisto VA (1995) Exercise-induced hypoglycemia in IDDM patients treated with a short-acting insulin analogue. Diabetologia 38: 106-111

72. Rönnemaa T, Viikari J (1998) Reducing snacks when switching from conventional soluble to lispro insulin treatment:effects on glycaemic control and hypoglycaemia. Diabet Med 15: 601-607

73. Binder C (1969) Absorption of injected insulin. A clinicalpharmacological study. Acta Pharmacol Toxicol (Copenh) 27[Suppl 2]:1-84

74. ter Braak EW, Woodworth JR, Bianchi R et al. (1996) Injection site effects on the pharmacokinetics and glucodynamics of insulin lispro and regular insulin. Diabetes Care 19: $1437-1440$

75. Fineberg NS, Fineberg SE, Anderson JH et al. (1996) Immunologic effects of insulin lispro [Lys(B28), Pro(B29) human insulin] in IDDM and NIDDM patients previously treated with insulin. Diabetes 45: 1750-1754

76. Lahtela JT, Knip M, Paul R, Antonen J, Salmi J (1997) Severe antibody-mediated human insulin resistance:successful treatment with the insulin analog lispro. Diabetes Care 20: 71-73

77. Henrichs HR, Unger H, Trautmann ME, Pfützner A (1996) Severe insulin resistance treated with insulin lispro. Lancet 348: 1248

78. Kumar D (1997) Lispro analog for treatment of generalized alleregy to human insulin. Diabetes Care 20:1357-1359

79. Meier M, Brand J, Standl E, Schnell O (1998) Successful treatment with insulin analog lispro in IDDM with delayed absorption of subcutaneously applied human regular insulin and complicated intraperitoneal insulin infusion. A case report. Diabetes Care 21: 1044-1045

80. Kotsanos JG, Vignati L, Huster W et al. (1997) Health-related quality-of-life results from multinational clinical trials of insulin lispro. Diabetes Care 20: 948-958

81. Bastyr EJ III, Holcombe JH, Anderson JH, Clore JN (1997) Mixing insulin lispro with ultralente insulin. Diabetes Care 20: $1047-1048$

82. Joseph SE, Korzon-Burakowska A, Woodworth JR et al. (1998) The action profile of lispro is not blunted by mixing in the syringe with NPH insulin. Diabetes Care 21: 2098-2102

83. Zinman B, Ross S, Campos RV et al. (1999) Effectiveness of human ultralente versus NPH insulin in providing basal insulin replacement for an insulin lispro multiple daily injection regimen. Diabetes Care 22: 603-608

84. Pampanelli S, Torlone E, Lalli C et al. (1995) Improved postprandial metabolic control after subcutaneous injection of a 
short acting insulin analogue in IDDM of short duration with residual pancreatic beta cell function. Diabetes Care 18: 1452-1459

85. Heinemann L, Heise T, Wahl LC et al. (1996) Prandial glycaemia after a carbohydrate-rich meal in Type 1 diabetic patients:using the rapid acting insulin analogue [Lys(B28), Pro(B29)] human insulin. Diabet Med 13: 625-629

86. Holcombe JH, Brunelle R, Zalani S, Deeb LC (1998) Comparative study of insulin lispro and regular insulin in prepubertal children with type 1 diabetes. Diabetes 47[Suppl 1]:A96 (Abstract)

87. Rutledge KS, Chase HP, Klingensmith GJ et al. (1997) Effectiveness of postprandial Humalog in toddlers with diabetes. Pediatrics 100: 968-972

88. Wallensteen M, Dahlquist G, Persson B et al. (1988) Factors influencing the magnitude, duration and the rate of fall of Bcell function in type 1 (insulin-dependent) diabetic children followed for two years from their clinical diagnosis. Diabetologia 31: 664-669

89. Jovanovic L, Ilic S, Pettit DJ et al. (1999) The metabolic and immunological effects of insulin lispro in gestational diabetes. Diabetes Care 22: 1422-1427

90. Garg SK, Pennington M, Gottlieb P et al. (1999) Comparison of maternal and fetal outcomes between human regular and Humalog ${ }^{\circledR}$ insulin treated pregnancies in type 1 diabetes. Diabetes 48[Suppl 1]:A61(Abstract)

91. Kitzmiller JL, Main E, Ward B et al. (1999) Insulin lispro and the development of proliferative diabetic retinopathy during pregnancy. Diabetes Care 22: 874-875

92. Jovanovic L (1999) Retinopathy risk:what is responsible? Hormones, hyperglycemia, or Humalog? Response to Kitzmiller et al. Diabetes Care 22: 846-848

93. Torlone E, Lalli C, Del Sindaco P et al. (1999) Optimization of postprandial blood glucose with lispro insulin in T2DM. Diabetes 48[Suppl 1]:A357 (Abstract)

94. Feinglos MN, Thacker CH, English J, Bethel MA, Lane JD (1997) Modification of postprandial hyperglycemia with insulin lispro improves glucose control in patients with type 2 diabetes. Diabetes Care 20: 1539-1542

95. Bruttomesso D, Pianta A, Mari A et al. (1999) Restoration of early rise in plasma insulin levels improves the glucose tolerance of type 2 diabetic patients. Diabetes 48: 99-105

96. Kang S, Creagh FM, Peters JR et al. (1991) Comparison of subcutaneous soluble human insulin and insulin analogues (AspB9, GluB27; AspB10; AspB28) on meal-related plasma glucose excursions in type 1 diabetic subjects. Diabetes Care 14: $571-577$

97. Brange J, Vølund A (1999) Insulin analogs with improved pharmacokinetic profile. Adv Drug Delivery Rev 35: 307-335

98. Owens DR, Kang S, Luzio S, Coates P (1993) Clinical results of phase I studies with insulin analogues. In: Berger M, Gries FA (eds) Frontiers in insulin pharmacology. Thieme, Stuttgart, pp 79-86

99. Hansen BF, Danielsen GM, Drejer K et al. (1996) Sustained signalling from the insulin receptor after stimulation with insulin analogues exibiting increased mitogenic potency. Biochem J 315: 271-279

100. Jørgensen LN, Didriksen LH (1993) Preclinical studies of rapid-acting insulin analogues. In: Berger M, Gries FA (eds) Frontiers in insulin pharmacology. Thieme, Stuttgart, pp 110-117

101. Ottesen JL, Nilsson P, Jami J et al. (1994) The potential immunogenicity of human insulin and insulin analogues evaluated in a transgenic mouse model. Diabetologia 37: 1178-1185

102. Heinemann L, Heise T, Jorgensen LN, Starke AAR (1993) Action profile of the rapid acting insulin analogue:human insulin B28Asp. Diabet Med 10: 535-539

103. Home P, Barriocanal L, Lindholm A (1999) Comparative pharmacokinetics and pharmacodynamics of the novel rapid- acting insulin analogue, insulin aspart, in healthy volunteers. Eur J Clin Pharmacol 55: 199-203

104. Heinemann L, Weyer C, Rauhaus M, Heinrich S, Heise T (1998) Variability of the metabolic effects of soluble insulin and the rapid acting insulin analogue insulin aspart. Diabetes Care 21: 1914-1919

105. Lindholm A, McEwen J, Riis AP (1999) Improved postprandial glycemic control with insulin aspart:a randomized double-blind cross-over trial in type 1 diabetes. Diabetes Care 22: 801-805

106. Home PD, Lindholm A, Hylleberg B, Round P, for the UK Insulin Aspart Study Group (1998) Improved glycaemic control with Insulin Aspart - a multicentre randomized, doubleblind cross-over trial in type 1 diabetic patients. Diabetes Care 21: 1904-1909

107. Home PD, Lindholm A, Riis AP, For The European Insulin Aspart Study Group (1999) Improved long-term blood glucose control with insulin aspart versus human insulin in people with type 1 diabetes. Diabetes 48[Suppl 1]:A358(Abstract)

108. Nielsen FS, Jørgensen LN, Ipsen M, Voldsgaard AI, Parving $\mathrm{H}-\mathrm{H}$ (1995) Long-term comparison of human insulin analogue B10Asp and soluble human insulin in IDDM patients on a basal/bolus insulin regimen. Diabetologia 38: 592-598

109. Jacobs MAJM, Keulen ETP, Kanc K et al. (1997) Metabolic efficacy of preprandial administration of Lys(B28),Pro(B29) human insulin analog in IDDM patients. Diabetes Care 20: 1279-1286

110. Raskin P, McGill J, Kilo C, Boss AH (1999) Human insulin analog (Insulin Aspart, IAsp) is comparable to human insulin in type 2 diabetes. Diabetes 48[Suppl 1]:A355(Abstract)

111. Rosenfalck AM, Thorsby P, Kjems L et al. (1999) Effects of the rapid-acting insulin analogue insulin aspart on postprandial glycaemic excursions compared to human soluble insulin actrapid given immediately or 30 minutes before a meal in insulin treated type 2 diabetes patients. Diabetes 48[Suppl 1]:A116(Abstract)

112. Halberg IB, Jacobsen LV, Dahl UL (1999) A study on selfmixing insulin aspart with NPH insulin in the syringe before injection. Diabetes 48[Suppl 1]:A104(Abstract)

113. Ceriello A (1998) The emerging role of post-prandial hyperglycaemic spikes in the pathogenesis of diabetic complications. Diabet Med 15: 188-193

114. Perriello G, De Feo P, Torlone E et al. (1991) The dawn phenomenon in Type 1 (insulin-dependent) diabetes mellitus:magnitude, frequency, variability, and dependency on glucose counterregulation and insulin sensitivity. Diabetologia 34: $21-28$

115. Perriello G, De Feo P, Torlone E et al. (1990) Nocturnal spikes of growth hormone secretion cause the dawn phenomenon in Type 1 (insulin-dependent) diabetes mellitus by decreasing hepatic (and extrahepatic) sensitivity to insulin in the absence of insulin waning. Diabetologia 33: 52-59

116. Koivisto VA, Yki-Järvinen H, Helve E, Karonen S-L, Pelkonen R (1986) Pathogenesis and prevention of the dawn phenomenon in diabetic patients treated with CSII. Diabetes 35: $78-82$

117. Bolli GB, Perriello G, Fanelli CG, De Feo P (1993) Nocturnal blood glucose control in type 1 diabetes mellitus. Diabetes Care 16[Suppl 3]:S71-S89

118. Bolli GB (1999) How to ameliorate the problem of hypoglycemia in intensive as well as non-intensive treatment of type 1 diabetes. Diabetes Care 22[Suppl 2]:B43-B52

119. Pramming S, Thorsteinsson B, Bendtson I, Ronn B, Binder C (1985) Nocturnal hypoglycaemia in patients receiving conventional treatment with insulin. BMJ 291: 376-379

120. Fanelli CG, Paramore DS, Hershey T et al. (1998) Impact of nocturnal hypoglycemia on hypoglycemic cognitive dysfunction in type 1 diabetes. Diabetes 47: 1920-1927 
121. Veneman T, Mitrakou A, Mokan M, Cryer P, Gerich J (1993) Induction of hypoglycemia unawareness by asymptomatic nocturnal hypoglycemia. Diabetes 42: 1233-1237

122. Kanc K, Janssen MMJ, Keulen ETP et al. (1998) Substitution of night-time continuous subcutaneous insulin infusion therapy for bedtime NPH insulin in a multiple injection regimen improves counterregulatory hormonal responses and warning symptoms of hypoglycaemia in IDDM. Diabetologia 41: 322-329

123. Jones TW, Porter P, Sherwin RS et al. (1998) Decreased epinephrine response to hypoglycemia during sleep. N Engl J Med 338: 1657-1662

124. Perriello G, De Feo P, Torlone E et al. (1988) The effect of asymptomatic nocturnal hypoglycemia on glycemic control in diabetes mellitus. N Engl J Med 319: 1233-1239

125. Fowelin J, Attvall S, von Schenck H, Smith U, Lager I (1990) Postprandial hyperglycaemia following a morning hypoglycaemia in Type 1 diabetes mellitus. Diabet Med 7: 156-161

126. Markussen J, Hougaard P, Ribel U, Sørensen AR, Sørensen E (1987) Soluble prolonged-acting insulin derivatives. I. Degree of protraction and crystallizability of insulins substituted in the termini of the B-chain. Protein Eng 1: 205-213

127. Markussen J, Havelund S, Kurtzhals P et al. (1996) Soluble fatty acid acylated insulins bind to albumin and show protracted action in pigs. Diabetologia 39: 281-288

128. Galloway JA, Hooper SA, Spradlin CT et al. (1992) Biosynthetic human proinsulin. Review of chemistry, in vitro and in vivo receptor binding, animal and human pharmacology studies, and clinical trial experience. Diabetes Care 15: 666-692

129. Heinemann L, Heise T, Klepper A et al. (1995) Time-action profiles of the intermediate-acting insulin analogue des(64,65)-human proinsulin. Diabetes Metab 21: 415-419

130. Jørgensen S, Vaag A, Langkjaer L, Hougaard P, Markussen J (1989) NovoSol Basal:pharmacokinetics of a novel soluble long acting insulin analog. BMJ 299: 415-419

131. Bähr M, Kolter T, Seipke G, Eckel J (1997) Growth promoting and metabolic activity of the human insulin analogue [GlyA21,ArgB31,ArgB32]insulin (HOE 901) in muscle cells. Eur J Pharmacol 320: 259-265

132. Berti L, Kellerer M, Bossenmaier B et al. (1998) The long acting human insulin analog HOE 901:charcteristics of insulin signalling in comparison to $\mathrm{Asp}(\mathrm{B} 10)$ and regular insulin. Horm Metab Res 30: 123-129

133. Dreyer M, Pein M, Schmidt C et al. (1994) Comparison of the pharmacokinetics/dynamics of Gly(A21)-Arg(B31,B32)-human-insulin (HOE71GT) with NPH-insulin following subcutaneous injection by using euglycaemic clamp technique. Diabetologia 37[Suppl 1]:A78(Abstract)

134. Lepore M, Kurzhals R, Pampanelli S et al. (1999) Pharmacokinetics and dynamics of s.c. injection of the long-acting insulin glargine (HOE901) in T1DM. Diabetes 48[Suppl 1]:A97(Abstract)

135. Luzio SD, Owens D, Evans M et al. (1999) Comparison of the s. c. absorption of HOE 901 and NPH human insulin in type 2 diabetic subjects. Diabetes 48[Suppl 1]:A111(Abstract)

136. Owens D, Luzio S, Tinbergen J, Kurzhals R (1998) The absorption of HOE 901 in healthy subjects. Diabetologia 41[Suppl 1]:A245(Abstract)

137. Talaulicar M, Willms B, Rosskamp R (1996) HOE 901, ein neues insulinanalogon, zur substitution des basalen insulinbedarfs bei Typ-I-diabetes. Diabetes und Stoffwechsel 5: 3-6

138. Pieber T, Eugene-Jolchine I, Derobert E (1998) Efficacy and safety of HOE 901 in patients with type 1 diabetes:a four- week randomised, NPH insulin-controlled trial. Diabetes 47[Suppl 1]:A62(Abstract)

139. Rosenstock J, Park G, Zimmerman J (1998) Efficacy and safety of HOE 901 in patients with type 1 DM:a four-week randomized, NPH insulin-controlled trial. Diabetes 47[Suppl 1]:A92(Abstract)

140. Ratner RE, Hirsch IB, Mecca TE, Wilson CA (1999) Efficacy and safety of insulin glargine in subjects with type 1 diabetes:a 28 week randomized, NPH insulin-controlled trial. Diabetes 48[Suppl 1]:A120(Abstract)

141. Rosenstock J, Schwartz S, Clark C, Edwards M, Donley D (1999) Efficacy and safety of HOE 901 (insulin glargine) in subjects with type $2 \mathrm{DM}$ :a 28-week randomized, NPH insulin-controlled trial. Diabetes 48[Suppl 1]:A100(Abstract)

142. Home P (1999) Insulin glargine:the first clinically useful extended-acting insulin in half a century? Exp Opin Invest Drugs 8: 307-313

143. Kurtzhals P, Havelund S, Jonassen I et al. (1995) Albumin binding of insulin acylated with fatty acids:characterization of the ligand-protein interaction and correlation between binding affinity and timing of the insulin effect in vivo. Biochem J 312: 725-731

144. Strange P, McGill J, Mazzeo M (1999) Reduced pharmacokinetic (PK) variability of a novel, long-acting insulin analog. Diabetes 48[Suppl 1]:A103(Abstract)

145. Kurtzhals P, Havelund S, Johanssen I, Markussen J (1997) Effect of fatty acids and selected drugs on the albumin binding of a long-acting, acylated insulin analogue. J Pharm Sci 86: $1365-1368$

146. Heinemann L, Sinha K, Weyer C et al. (1999) Time-action profile of the soluble, fatty acid acylated, long-acting insulin analogue NN304. Diabet Med 16: 332-338

147. Myers SR, Yakubu-Madus FE, Johnson WT et al. (1997) Acylation of human insulin with palmitic acid extends the time action of human insulin in diabetic dogs. Diabetes 46: 637-642

148. Radziuk J, Pye S, Bradley B et al. (1998) Basal activity profiles of NPH and [ $\mathrm{N}^{\varepsilon}$-palmitoyl Lys (B29)] human insulins in subjects with IDDM. Diabetologia 41: 116-120

149. Radziuk J, Pye S, Bradley B et al. (1998) Basal activity profiles of NPH and [ $\mathrm{N}^{\varepsilon}$-palmitoyl Lys (B29)] human insulins in subjects with IDDM. Erratum. Diabetologia 41: 489-490

150. Brader ML, Millican RL, Brems DN et al. (1997) Effects of surface hydrophobicity on the structural properties of insulin. In: Marshak DR (ed) Techniques in Protein Chemistry VIII. Academic Press, San Diego, pp 289-297

151. Janssen MMJ, Casteleijn S, Deville W et al. (1997) Nighttime insulin kinetics and glycemic control in type 1 diabetes patients following administration of an intermediate-acting lispro preparation. Diabetes Care 20: 1870-1873

152. Weyer C, Heise T, Heinemann L (1997) Insulin aspart in a 30/ 70 premixed formulation. Pharmacodynamic properties of rapid-acting insulin analog in stable mixture. Diabetes Care 20: $1612-1614$

153. Heise T, Weyer C, Serwas A et al. (1998) Time-action profiles of novel premixed preparations of insulin lispro and NPL insulin. Diabetes Care 21: 800-803

154. Koivisto VA, Tuominen JA, Ebeling P (1999) Lispro Mix 25 insulin as a premeal therapy in type 2 diabetic patients. Diabetes Care 22: 459-462

155. Roach P, Yue L, Arora V, and The Humalog Mix25 Study Group (1999) Improved postprandial glycemic control during treatment with Humalog Mix 25, a novel protamine-based insulin lispro formulation. Diabetes Care 22: 1258-1261 